\title{
Desire or Dread from Nucleus Accumbens Inhibitions: Reversed by Same-Site Optogenetic Excitations
}

\author{
๑Hannah M. Baumgartner, ${ }^{1 \star}$ Shannon L. Cole,${ }^{2 \star}$ Jeffrey J. Olney, ${ }^{1}$ and $\odot$ Kent C. Berridge \\ ${ }^{1}$ Department of Psychology, University of Michigan, Ann Arbor, Michigan 48109, and ${ }^{2}$ Department of Anatomy and Neurobiology, University of Maryland \\ School of Medicine, Baltimore, Maryland 21201
}

Microinjections of a glutamate AMPA antagonist (DNQX) in medial shell of nucleus accumbens (NAc) can cause either intense appetitive motivation (i.e., 'desire') or intense defensive motivation (i.e., 'dread'), depending on site along a flexible rostrocaudal gradient and on environmental ambience. DNQX, by blocking excitatory AMPA glutamate inputs, is hypothesized to produce relative inhibitions of NAc neurons. However, given potential alternative explanations, it is not known whether neuronal inhibition is in fact necessary for NAc DNQX microinjections to generate motivations. Here we provide a direct test of whether local neuronal inhibition in NAc is necessary for DNQX microinjections to produce either desire or dread. We used optogenetic channelrhodopsin (ChR2) excitations at the same local sites in NAc as DNQX microinjections to oppose relative neuronal inhibitions induced by DNQX in female and male rats. We found that same-site ChR2 excitation effectively reversed the ability of NAc DNQX microinjections to generate appetitive motivation, and similarly reversed ability of DNQX microinjections to generate defensive motivation. Same-site NAc optogenetic excitations also attenuated recruitment of Fos expression in other limbic structures throughout the brain, which was otherwise elevated by NAc DNQX microinjections that generated motivation. However, to successfully reverse motivation generation, an optic fiber tip for ChR2 illumination needed to be located within $<1 \mathrm{~mm}$ of the corresponding DNQX microinjector tip; that is, both truly at the same NAc site. Thus, we confirm that localized NAc neuronal inhibition is required for AMPA-blocking microinjections in medial shell to induce either positively-valenced 'desire' or negatively-valenced 'dread'.

Key words: accumbens; eating; fear; Fos; motivation; optogenetics

Significance Statement

A major hypothesis posits neuronal inhibitions in nucleus accumbens generate intense motivation. Microinjections in nucleus accumbens of glutamate antagonist, DNQX, which might suppress local neuronal firing, generate either appetitive or defensive motivation, depending on site and environmental factors. Is neuronal inhibition in nucleus accumbens required for such pharmacologically-induced motivations? Here we demonstrate that neuronal inhibition is necessary to generate appetitive or defensive motivations, using local optogenetic excitations to oppose putative DNQX-induced inhibitions. We show that excitation at the same site prevents DNQX microinjections from recruiting downstream limbic structures into neurobiological activation, and simultaneously prevents generation of either appetitive or defensive motivated behaviors. These results may be relevant to roles of nucleus accumbens mechanisms in pathological motivations, including addiction and paranoia.

\section{Introduction}

Localized neuropharmacological glutamate blockade at sites in the medial shell of nucleus accumbens (NAc), by microinjections

\footnotetext{
Received Dec. 3, 2019; revised Jan. 22, 2020; accepted Feb. 10, 2020.

Author contributions: H.M.B., S.L.C., J.J.O., and K.C.B. designed research; H.M.B., S.L.C., and J.J.0. performed research; H.M.B. and J.J.O. analyzed data; H.M.B., S.L.C., J.J.O., and K.C.B. wrote the paper.

This work was supported by National Institutes of Health Grants (MH063649 and DA015188) to K.C.B., by F31 DA047738 and T32 DA007281 to H.M.B., by DA007267 to S.L.C., and by DA007268 and DC00011 to J.J.0. We thank Marco Liera for technical assistance, and Nina Mostovoi and Elizabeth Hubbard for behavioral testing and histology. The authors declare no competing financial interests.

*H.M.B. and S.L.C. contributed equally to this work.

Correspondence should be addressed to Hannah M. Baumgartner at hmbaum@umich.edu or Shannon L. Cole at ShannonCole@som.umaryland.edu.
}

of the glutamate AMPA antagonist, DNQX, produce either intense appetitive behavior or fearful behavior. Valence depends partly on site placement along a rostrocaudal gradient. Rostral shell microinjections of DNQX produce increased appetitive motivation, such as increased eating and food intake, and establish conditioned place preferences (Maldonado-Irizarry et al., 1995; Reynolds and Berridge, 2003). By contrast, caudal shell DNQX microinjections can instead elicit active-coping forms of 'fearful' behaviors, such as anti-predator defensive treading-burying, 
fearful vocalizations to touch, and establish conditioned place avoidance (Reynolds and Berridge, 2001, 2002, 2008; Faure et al., 2010; Richard and Berridge, 2011; Richard et al., 2013). Beyond anatomical determinants, the motivational valence produced by DNQX microinjections at many shell sites can be shifted by changes in the emotional ambience or stress levels of the external environment (Reynolds and Berridge, 2008; Richard and Berridge, 2011).

What underlying neurobiological mechanisms are responsible for this NAc-generated 'desire' or 'dread'? A major neurobiological hypothesis has been that reward motivation is generated via relative neurophysiological inhibition of NAc medium spiny neurons (MSNs; Carlezon and Wise, 1996; Cheer et al., 2005; Taha and Fields, 2006; Meredith et al., 2008; Roitman et al., 2008; Wheeler et al., 2008; Carlezon and Thomas, 2009; Krause et al., 2010). By this hypothesis, NAc neuronal inhibition of MSNs shuts off axonal GABA release from projections to anatomical targets in lateral hypothalamus (LH), ventral pallidum (VP), and ventral tegmental area (VTA), releasing those targets from tonic GABAergic suppression, and disinhibiting them into relative excitation to generate intense motivation (Mogenson et al., 1983; Zahm and Heimer, 1990; Heimer et al., 1991; Lu et al., 1998; Usuda et al., 1998; Zhou et al., 2003; Humphries and Prescott, 2010).

This NAc-inhibition hypothesis also has plausibility when applied to DNQX microinjections, to the extent that local AMPA blockade suppresses the ability of excitatory glutamate signals from cortex, hippocampus, or basolateral amygdala to produce local EPSPs in MSNs. This would produce at least relative inhibition of those local MSNs, by suppressing activity below normal levels.

However, as yet, there is no direct evidence that neuronal inhibition is actually necessary NAc for DNQX microinjections to generate either appetitive or fearful motivations. Alternatively, other pharmacologically-induced postsynaptic neurochemical and second messenger effects of the drugs induced in parallel with electrophysiological changes, as well as presynaptic antagonist effects, might cause the motivated behaviors (Tarazi et al., 1998a,b; Menuz et al., 2007; Lee et al., 2010).

Here, we directly tested the hypothesis that local neuronal inhibition is necessary for DNQX microinjections in NAc to induce intense motivated behaviors. This was done by locally opposing putative DNQX-inhibition of NAc neurons at the microinjection site by adding optogenetic channelrhodopsin (ChR2) excitation at the same NAc site. Our results indicate that localized ChR2 excitation at the same site of a DNQX microinjection reverses both positively-valenced 'desire' and negatively-valenced 'dread' induced by DNQX microinjections at their corresponding rostrocaudal sites in NAc medial shell. Both motivational reversals occurred only if ChR2 optic fiber tip and DNQX microinjector tip were within $0.5 \mathrm{~mm}$ (or at least $0.8 \mathrm{~mm}$ ) of each other in shell, but not if the fiber tip and microinjector tip are spaced further apart. Laser-induced behavioral reversals of DNQX effects were also accompanied by neurobiological reversal of recruitment of Fos increases in LH, VP, VTA, and other limbic structures, that were otherwise induced by NAc DNQX microinjections. These results help confirm the necessity of relative NAc inhibition, and support the release of downstream targets into excitation, for NAc DNQX microinjections to generate appetitive or defensive motivations.

\section{Materials and Methods}

Subjects. Forty-nine rats (Sprague-Dawley or Long-Evans obtained from Envigo or bred in-house; $n=5$ females, $n=43$ males; $300-500 \mathrm{~g}$ ) were implanted with bilateral NAc cannula for drug microinjection, and received bilateral virus microinfusions (ChR2 or eYFP) and bilateral optic fibers implanted at the same individualized sites in medial shell of NAc. Sites were bilaterally identical within an individual, but were staggered across individuals so that the group as a whole filled most of the NAc medial shell. Rats were housed in same-sex pairs or groups of three on a $12 \mathrm{~h}$ reverse light/dark cycle at $\sim 21^{\circ} \mathrm{C}$ with ad libitum access to food (Purina Rat Chow) and water. All experimental procedures were approved by the University Committee on the Use and Care of Animals at the University of Michigan and performed in accordance with the guidelines on animal care and use by the National Institutes of Health.

Experimental groups. (1) Standard laboratory, within-subject group: 14 total (Sprague-Dawley, all male). (2) Stressful environment, withinsubject group: 11 total (Long-Evans; 5 female, 6 male). (3) Standard laboratory Fos mapping, between-subject group: 24 total (SpragueDawley, all male).

Three separate groups of rats were run. Two groups compared withinsubject behavior of the same individuals after four different NAc microinjection/laser conditions (within-subject comparison groups): DNQX microinjection alone, DNQX microinjection plus laser illumination during test, vehicle microinjection alone, and vehicle microinjections plus laser illumination during test. These two within-subject groups differed in the rat strain and emotional ambience of their external environment used to test behavior after NAc microinjections. The first within-subject group used Sprague-Dawley rats tested in a standard laboratory environment (standard laboratory environment groups). The second withinsubject group added loud sound to the behavioral test environment, in the form of raucous music, intended to raise potential stress levels to facilitate DNQX-elicitation of defensive treading-burying behavior as a fearful anti-predator reaction, and used Long-Evans rats, as they may potentially have greater emotional-reactivity to stress than SpragueDawley rats (De Boer and Koolhaas, 2003; stressful environment group). The third group provided between-subject behavioral comparisons, and allowed measurement of the size of local Fos plumes in NAc induced by each microinjection/laser condition, and changes in distant Fos expression in other limbic structures accompanying those conditions (Fos mapping; between-subject condition). Because repetition of microinjections can induce local gliosis or necrosis at a microinjection site that impedes drug spread, potentially reducing Fos plume size of a final drug microinjection and reducing behavioral effects elicited by the drug microinjection (Richard and Berridge, 2011; Castro and Berridge, 2017), each rat in this between-subject group was tested behaviorally only once with a single microinjection/optogenetic condition (individuals assigned in counterbalanced numbers to each of the 4 conditions). Brains were processed for Fos expression immediately afterward. This avoided underestimation of NAc Fos plume sizes, which would have distorted assessment of whether DNQX microinjection plumes and ChR2 laser illumination plumes anatomically overlapped in a given rat.

Cranial cannulation and fiber implantation surgery. Rats were anesthetized using isoflurane ( $5 \%$ induction, maintenance at $1-2 \%$ ), and pretreated with atropine $(.05 \mathrm{mg} / \mathrm{kg}$, i.p.) to prevent respiratory distress. Carprofen $(5.0 \mathrm{mg} / \mathrm{kg}$, s.c.) was additionally administered for postsurgical analgesia, and cefazolin ( $75 \mathrm{mg} / \mathrm{kg}$, s.c.) was administered to prevent infection. Rats were positioned in a stereotaxic apparatus (David Kopf Instruments), with the mouth bar set to $5.0 \mathrm{~mm}$ above intra-aural for cannula insertion, with the head flat using a lateral 16 degree angle for optic fiber insertion to avoid the cannula path and not penetrate lateral ventricles, and to achieve positioning of fiber/cannula tips closely together (Fig. 1). Bilateral stainless-steel microinjection guide cannulae (14 $\mathrm{mm}, 23$-gauge) and bilateral optic fibers ( $\sim 8-9 \mathrm{~mm}$ in length) were aimed at matching NAc sites. Guide cannula ended $2 \mathrm{~mm}$ above the optic tips, because microinjector tips extended $2.0 \mathrm{~mm}$ beyond the end of the guide cannulae, and sites for the optic fiber tip and microinjector tip were intended to be identical ( $7.6 \mathrm{~mm}$ on the dorsoventral plane). Bilateral sites were also identical for a given rat. However, site coordinates were 


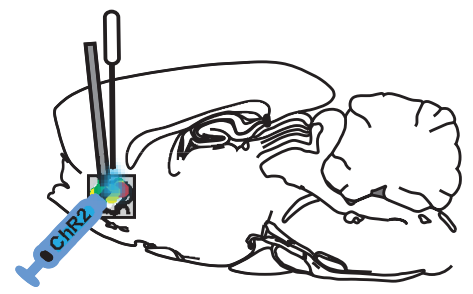

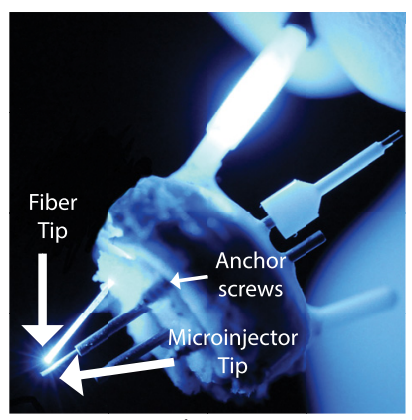

Hi
DNQX Alone

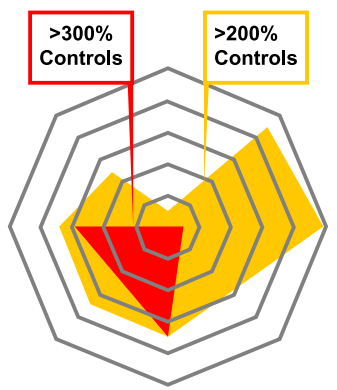

Inner Plume Radius $=94 \mu \mathrm{m}$ 1

Outer Plume Radius $=288 \mu \mathrm{m}$

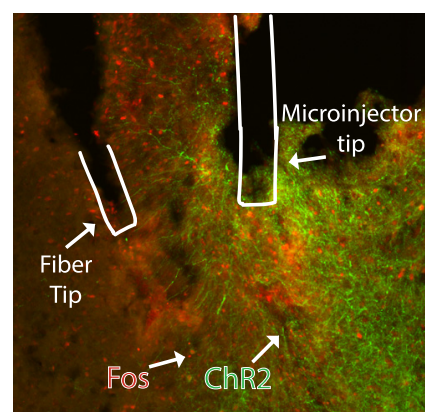

$1 \mathrm{~mm}$

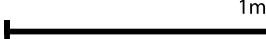

ChR2 Laser Alone

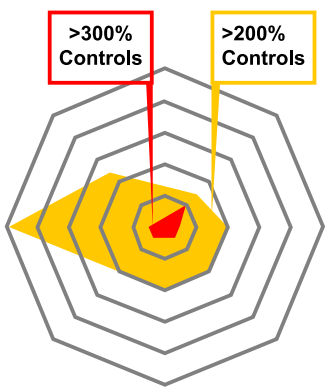

Inner Plume Radius $=\mathbf{3 8} \mu \mathrm{m}$ H

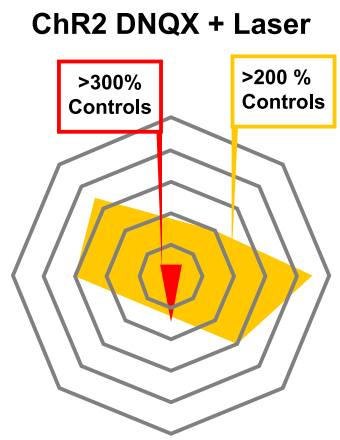

Inner Plume Radius $=\mathbf{3 1} \boldsymbol{\mu m}$ H
Outer Plume Radius $=206 \mu \mathrm{m}$

Rats were monitored daily postoperatively for $7 \mathrm{~d}$. Each rat received another dose of carprofen for additional pain relief after $24 \mathrm{~h}$, and received topical reapplications of antibiotic ointment around the skullcap every day for the week. Approximately 4 weeks were allowed before behavioral testing to allow virus incubation and adequate ChR2 expression.

Post-test site verification. All optic fiber and microinjection sites were verified histologically after the experiments were completed. Any rat that had fiber optic tips and microinjector tips within $<1 \mathrm{~mm}$ of each other on at least one side of in medial shell was considered to have potentially overlapping or aligned NAc sites for optogenetic stimulation and drug microinjections (aligned fiber/microinjector tips; see Fos plume results). Any rat with fiber optic tips more distant than $1.0 \mathrm{~mm}$ away from microinjector tip was considered to have misaligned tips. Aligned versus misaligned groups were statistically compared separately to assess if behavioral effects for laser modulation of DNQX-induced motivations differed depending on proximity of fiber tips to microinjector tips.

Handling and habituation. For 2-3 d before behavioral testing began, rats were handled for at least $15 \mathrm{~min} / \mathrm{d}$ for acclimation. Then for 4 additional habituation days, rats were connected to optogenetic laser delivery cables and placed in the test chamber for $1 \mathrm{~h} / \mathrm{d}$. The behavioral test chamber permitted ad libitum access to food and water, and contained cob bedding as a substrate to support potential defensive treading/burying. Laser power supplies were turned on during these habituation sessions so rats became accustomed to their ambient sound, but laser output to cables was turned off. On the fourth day of chamber habituation, rats received an intra-accumbens microinjection of vehicle solution before being placed into the test chamber, to habituate them to all aspects of receiving a microinjection and handling procedures.

Intracranial microinjections for behavioral testing. Drug microinjections were administered bilaterally. Rats received either the AMPA antagonist DNQX dissolved in vehicle (220 ng/0.5 $\mu \mathrm{l} /$ side; Sigma-Aldrich) or vehicle

staggered across rats so that the group's collective sites filled the entire rostrocaudal extent of NAc medial shell [ranging between anteroposterior (AP): $+2.2+3.0$; mediolateral $(\mathrm{ML}): \pm 0.8+1.2 \mathrm{~mm}$, and dorsoventral (DV): $-7.6 \mathrm{~mm}$; all relative to bregma].

During the surgery, the microinjector was inserted into the guide cannula, and each rat received bilateral $0.5 \mu \mathrm{l}$ microinfusions of either AAV5-hSYN-ChR2-eYFP virus (UNC Vector Core, Chapel Hill, NC; rate $=0.1 \mu \mathrm{l} / \mathrm{min} ; 5 \mathrm{~min}$ duration; ChR2 rats) or optically inactive control virus that lacked ChR2 (AAV5-HSYN-eYFP, UNC Vector Core; control eYFP rats). After microinfusions, the virus was allowed to diffuse for 10 min before withdrawing microinjector cannula.

Next, optic fiber implants were inserted in a flat-skull position at a $16^{\circ}$ lateral angle, triangulating the aim of the optic fiber tip to closely approach the microinjector cannula tip without following the same track. Optic fiber implants were always aimed at coordinates $\sim 0.3 \mathrm{~mm}$ above the microinjector tip, so that illumination would overlap with tissue containing the drug (AP: +1.0 to +2.5 ; ML: \pm 3.0 to $\pm 3.5 \mathrm{~mm}$; DV: -6.5 to -7.2 ; at $16^{\circ}$ lateral angle). External ends of microinjection guide cannula and fiber implants were secured to the skull with four surgical screws and dental acrylic. Stainless-steel stylets (28 gauge) were inserted into the guide cannulae to prevent infection and clotting. alone (50\% DMSO and 50\% $0.15 \mathrm{~m}$ saline). Vehicle/DNQX conditions counterbalanced across days for within-subject rats. Microinjections of $0.5 \mu \mathrm{l} /$ side were spaced $48 \mathrm{~h}$ apart on test days for within-subject groups to ensure that there were no lingering drug effects. A standard dose of DNQX at $220 \mathrm{ng} / 0.5 \mu \mathrm{l} /$ side was selected based on results of a previous study in our laboratory (Richard and Berridge, 2013), which indicated this DNQX dose to produce moderate levels of either appetitive behavior or defensive behavior, depending on rostrocaudal site in NAc medial shell.

To administer NAc microinjections, rats were individually taken out of their home cages and the experimenter removed the stylet protecting the guide cannulae. Rats were gently held in the experimenter's lap while microinjectors (16 mm, 29-gauge) connected to PE-20 delivery tubing were inserted into each guide cannula, and microinjections were made. Microinjections were administered at a rate of $0.3 \mu \mathrm{l} / \mathrm{min}$ using a microinjection syringe pump to deliver a total $0.5 \mu$ volume per side of NAc (Hamilton). After a DNQX or vehicle microinjection, microinjectors were left in place $\sim 1$ min to allow for drug diffusion. Stylets were replaced in guide cannulae after microinjectors were removed, fiber optic cables were attached, and rats were immediately put into the testing chamber. 
Optogenetic laser stimulation. Before all tests, two fiber optic cables were attached to a rat's bilateral fiber implants, so that laser could be bilaterally delivered to NAc. Laser power supplies were always turned on to keep fan sound constant, though laser was activated only during particular test sessions, as described in Behavioral testing. Fiber optic implant output was measured to be $>85 \%$ efficiency, and laser intensity was kept between 8 and $10 \mathrm{~mW}$ at tips. Laser illumination was programmed to deliver $5 \mathrm{~s}$ bins of $25 \mathrm{~Hz}$ ( $5 \mathrm{~ms}$ ON, $25 \mathrm{~ms}$ OFF) blue (473 nm) laser stimulation with $15 \mathrm{~s}$ in between the laser bins, and ON-OFF bins were cycled repeatedly throughout the whole $1 \mathrm{~h}$ test.

Behavioral testing. DNQX and laser effects on appetitive eating behavior and defensive behavior were measured in $1 \mathrm{~h}$ daily tests on four test days with the following conditions counterbalanced in order: (i) baseline condition (vehicle microinjection, no laser), (ii) Laser-alone condition (Laser stimulation, vehicle microinjection), (iii) DNQX-alone condition (DNQX but no laser), and (iv) combined DNQX-Laser condition (DNQX microinjection, laser stimulation). Tests were conducted in a transparent chamber $(25.5 \times 46 \times 46 \mathrm{~cm})$ containing at least $3 \mathrm{~cm}$ of granular corncob bedding on the floor, plus a water cup taped to the bottom on one side, and a pre-weighed amount of rat chow (25-30 g of Purina rat chow). The cob bedding provided material that rats could kick forward, as a substrate to support defensive treading/burying behavior. The room contained standard white ambient illumination (400-500 lux). Ambient sound levels were 50-60 decibels measured in test chamber. A video camera in front of each test chamber recorded behavior for subsequent slow-motion analysis.

Behavioral testing in sensory stressful environment. A separate group of rats $(n=11)$ underwent testing conditions as described, except in a laboratory environment with elevated levels of sound (rock music soundtrack: Iggy Pop, Hippodrome Paris 77; 80-87 decibels measured in chamber), intended to create a potentially more stressful ambience. Ambient light levels were identical to those in standard testing environment (400-500 lux).

Behavioral scoring of defensive reactions during retrieval at end of test. At the end of the testing session, the experimenter retrieved the rat with a gloved hand using a standardized set of slow-approach movement similar to previous studies (Richard and Berridge, 2011): (1) the experimenter approached the chamber with slow steps (taking $\sim 3 \mathrm{~s}$ ), (2) reached with one gloved hand inside the chamber to slowly approach the rat and stroke its side once (taking $\sim 3 \mathrm{~s}$ ), (3) inserted four fingers beneath the rat with palm up, and then (4) gently lifted the rat out of the chamber (taking $\sim 3 \mathrm{~s}$ ). Any audible distress calls, escape attempts, or bite attempts directed at the experimenter were recorded during the retrieval process. A bite attempt was counted if a rat attempted to contact the experimenter's hand with teeth. Escape attempts were counted if a rat rapidly moved away from a hand or attempted to climb the wall upon initial touch or lifting. Distress calls were noted any if audible vocalizations were made during the retrieval procedure.

Behavioral scoring of video records. Video-recorded behavior during tests was scored in slow motion (1/8-1/2 speed; Observer software, Noldus), by observers blind to experimental condition. Eating (actively chewing and swallowing food), defensive treading/burying, escape attempts (subject tries to move away from the experimenter's reach), were all measured as cumulative duration in seconds of each behavior. Bouts of eating (counted as the number of times eating was initiated after a pause of $>0.5 \mathrm{~s}$ ), bouts of treading (counted as the number of times treading was initiated after a pause of $>0.5 \mathrm{~s}$ ), and distress vocalizations were all counted as discrete events or bouts each time they occurred.

Brain histology. Thirty minutes after the end of the final behavioral testing session for within-subject groups, or after the single behavioral test session for the between-subject group, rats received an overdose of sodium pentobarbital $(0.8 \mathrm{ml})$, and were transcardially perfused (i.e., 90 min after final DNQX or vehicle microinjection for all groups). Brains were postfixed in paraformaldehyde for $2 \mathrm{~d}$ at $4^{\circ} \mathrm{C}$, then stored in a $25 \%$ sucrose solution at $4^{\circ} \mathrm{C}$ until later processing.

For immunohistochemistry, brains were sliced into $40 \mu \mathrm{m}$ sections using a cryostat (Leica). Tissue was rinsed for $10 \mathrm{~min}$ in $0.1 \mathrm{M}$ sodium phosphate buffer $(\mathrm{NaPB})$ three times, then blocked with $5 \%$ normal donkey serum for $30 \mathrm{~min}$. Tissue was incubated overnight at room tem-

\section{Table 1. Structures of interest for distributed Fos analysis}

Limbic brain structures in which distant Fos recruitment was assessed

BLA

BNST

CeA

IF

$\mathrm{LH}$

MeA

$\mathrm{NACC}$

PFA

VP

VTA

Fos was separately quantified in both anterior and posterior subregions of infralimbic cortex, and in bed nucleus of stria terminalis, lateral hypothalamus, and ventral pallidum.

perature in rabbit anti-cFos (1:1000; Millipore, catalog \#ABE457, lot \#3142408). Slices were rinsed three times for $10 \mathrm{~min}$ in $0.1 \mathrm{M} \mathrm{NaPB}$ before incubation with donkey anti-rabbit AlexaFluor 594 (1:300; Jackson Immunoresearch, code \#711-585-152; lot \#1827674) for $120 \mathrm{~min}$. Tissue was again rinsed for $10 \mathrm{~min}$ in $0.1 \mathrm{M} \mathrm{NaPB}$ three times and mounted onto slides. Images of the fiber and cannula tip were taken using a digital camera (QImaging) attached to a fluorescence microscope (Leica). Sites of optic fibers and of microinjection cannulae were identified and mapped onto coronal slices from a rat brain atlas (Paxinos and Watson, 2007), and positions were extrapolated and transferred onto a sagittal slice (Fig. 1).

Fos plume analysis. Local Fos plumes surrounding a fiber optic tip that was illuminated 90 min before perfusion, or surrounding the microinjector tip $90 \mathrm{~min}$ after a DNQX microinjection, reflect local changes in neuronal transcription induced by direct ChR2 photoexcitation or by DNQX neurochemical impact (compared with eYFP baseline or vehiclemicroinjection baseline as control groups). The diameter of a Fos plume provides an objective indicator of how far changes in neuronal activity induced by optogenetic stimulation or drug microinjection extend from the tips of fiber or cannula. Fos expression was measured with a fluorescent microscopy filter and excitation band at 515-545 $\mathrm{nm}$ to identify Fos-positive cells. Numbers of Fos-expressing cells were counted at $10 \times$ magnification within successive blocks $(50 \times 50 \mu \mathrm{m})$ of tissue emanating along eight radial arms centered at the optic fiber tip or microinjector tip. Counts continued outward along an arm until at least two sequential blocks contained zero Fos-labeled cells, which was taken as marking the terminal radius of the Fos plume along that arm. Intensities of Fos elevation in an illuminated ChR2 brain were calculated in terms of percentage change from a control baseline measured in rats receiving vehicle microinjections alone and/or illuminated eYFP inactive-virus control rats. That is, equivalent block locations from NAc of eYFP control rats that received laser illumination before perfusion similarly to ChR2 rats. Fos elevations in ChR2 blocks were denoted in increments of $>200 \%$ elevation or higher $>300 \%$ elevation above the baseline. Similarly, changes induced by DNQX microinjections were computed by comparison to a vehicle-microinjection baseline. For that, Fos was measured in equivalent sites in rats that received vehicle microinjections $90 \mathrm{~min}$ before perfusion (Castro and Berridge, 2017; Warlow et al., 2017; Cole et al., 2018).

Distant Fos expression. Recruitment of distant changes in Fos expression in other brain structures was also assessed to determine functional connectivity expressed in anatomical patterns of limbic Fos elevation following microinjection or optogenetic manipulations that altered motivated behaviors (for a list of structures, see Table 1). Within each structure or subregion, Fos-expressing neurons were counted in two to three separate sample boxes, placed approximately equidistantly within the structure, and at approximately the same locations across different rats. The size of sample boxes was specifically adjusted to each brain structure, so that each sample box contained $\sim 10$ Fos-expressing neurons in control rats that received vehicle microinjections in NAc. The number of Fos-expressing neurons within each box was counted separately for each NAc drug/laser condition as above and compared with the vehicle microinjection baseline, each measured in that particular corresponding brain structure or subregion in separate rats.

Experimental design and statistical analysis. To evaluate behavioral data, effects of drug microinjections, ChR2 laser stimulation, drug-laser interactions, anatomical site effects, and sex differences when necessary were assessed initially via mixed-model ANOVAs and subsequent pair- 
Table 2. Unilateral versus bilateral alignment of fiber/cannula tips for within-subjects groups

\begin{tabular}{|c|c|c|c|c|c|c|c|}
\hline $\begin{array}{l}\text { Test } \\
\text { environment }\end{array}$ & Placement & Cannulae & Fiber & $N$ & $\begin{array}{l}\text { DNQX } \\
\text { increase, \% }\end{array}$ & $\begin{array}{l}\text { Laser } \\
\text { suppression, \% }\end{array}$ & $\begin{array}{l}\text { Missed } \\
\text { target }\end{array}$ \\
\hline \multirow[t]{5}{*}{ Standard } & \multirow[t]{5}{*}{ All combined } & \multirow[t]{3}{*}{ Bilateral } & Bilateral aligned & 9 & Yes 300 & Yes $>50$ & - \\
\hline & & & Unilateral aligned & 0 & - & - & - \\
\hline & & & Misaligned & 4 & Yes 200 & No & AcbSh; VP; DS (fibers) \\
\hline & & \multirow[t]{2}{*}{ Unilateral } & Unilateral aligned & 0 & - & - & - \\
\hline & & & Misaligned & 1 & Yes 500 & No & LS (cannula); DS (fibers) \\
\hline \multirow[t]{10}{*}{ Stressful } & \multirow[t]{5}{*}{ Rostral } & \multirow[t]{3}{*}{ Bilateral } & Bilateral aligned & 3 & Yes 400 & Yes $>75$ & - \\
\hline & & & Unilateral aligned & 1 & Yes 250 & Yes $>80$ & DS (fiber) \\
\hline & & & Misaligned & 0 & - & - & - \\
\hline & & \multirow[t]{2}{*}{ Unilateral } & Unilateral aligned & 1 & Yes 1500 & Yes $>50$ & BNST (cannula/fiber) \\
\hline & & & Misaligned & 0 & - & - & - \\
\hline & \multirow[t]{5}{*}{ Caudal } & \multirow[t]{3}{*}{ Bilateral } & Bilateral aligned & 5 & Yes 700 & Yes $>50$ & 一 \\
\hline & & & Unilateral aligned & 1 & Yes 1200 & Yes 100 & DS (fiber) \\
\hline & & & Misaligned & 0 & - & - & 一 \\
\hline & & \multirow[t]{2}{*}{ Unilateral } & Unilateral aligned & 0 & - & - & 一 \\
\hline & & & Misaligned & 0 & - & - & - \\
\hline
\end{tabular}

In the current study, ChR2 laser reversed DNQX effects even in rats with aligned fiber-cannula tips on only one side of the NAc fiber. AcbSh, Nucleus accumbens shell; DS, dorsal striatum; LS, lateral septum.

wise post hoc comparisons with Bonferroni corrections. For nonnormally distributed data (i.e., time spent treading), nonparametric Kruskal-Wallis and follow-up Wilcoxon tests were used. Planned comparisons were used to compare Fos expression. For statistical analysis of anatomical sites, the NAc medial shell was divided into rostral and caudal halves: rats with AP coordinates $>1.2 \mathrm{~mm}$ ahead of bregma were placed in the rostral group, and those with sites $<1.2 \mathrm{~mm}$ ahead of bregma in the caudal group. Effects were considered statistically significant if $p<0.05$, two-tailed. Cohen's $d$, and $r=\frac{Z}{\sqrt{N_{1}+N_{2}}}$ for nonparametric tests, were used to calculate the magnitude of effect sizes.

\section{Results}

\section{Anatomical placements of optic fibers and microinjections in NAc}

Standard laboratory: within-subject group (Group 1)

NAc sites of optic fibers and microinjection cannulae were confirmed to be in the rostral half of the medial shell for 11 of 14 rats, and in the caudal half of medial shell for 3 remaining rats. To assess potential interaction between laser and drug at a given site, placements in one side of NAc shell that had optic fiber and microinjector tips anatomically aligned together (i.e., both tips $<0.5-0.8 \mathrm{~mm}$ apart, based on Fos plume sizes in next section) were distinguished from placements that were not aligned (i.e., fiber tip $>1 \mathrm{~mm}$ from cannula tip, even if both in the medial shell; Table 2). Rats that had $<0.5 \mathrm{~mm}$ aligned tips on both sides of NAc were considered bilaterally aligned $(n=7)$. Rats that had unilateral $<0.5 \mathrm{~mm}$ alignment on one side of NAc and $0.5 \mathrm{~mm}$ to $0.8 \mathrm{~mm}$ alignment on the contralateral side $(n=2)$ were considered provisionally aligned, and explicitly compared with bilaterally aligned rats for ChR2 laser effects on DNQX-elicited behaviors. Because these two groups showed comparable levels of laser-induced ChR2 suppression (laser ChR2 suppression for bilateral $<0.5 \mathrm{~mm}$ group $=62.0 \pm 13.6 \%$; suppression for unilateral $<0.5 \mathrm{~mm}$ and contralateral $0.5-0.8 \mathrm{~mm}$ group $=59.1 \pm$ $11.9 \%)$, they were combined in subsequent statistical analyses. No rats had unilateral $<0.5 \mathrm{~mm}$ alignment but non-aligned $>1$ mm placements on the contralateral side of NAc. Remaining rats had bilaterally non-aligned placements, with tips $>1 \mathrm{~mm}$ apart on both sides of NAc $(n=5)$ and were considered separately in statistical analyses.

\section{Local Fos plumes: zones of impact for DNQX microinjections and ChR2 laser stimulations}

DNQX microinjections and ChR2 fiber illumination both produced local Fos plumes of increased Fos expression immediately surrounding the cannula/fiber tips in NAc medial shell (Fig. 1). DNQX microinjections by themselves (without laser during the subsequent test) produced Fos plumes with $>300 \%$ intense increases in Fos over control levels measured at the same sites (i.e., after vehicle microinjections without laser) in a plume center of $94 \pm 51 \mu \mathrm{m}$ radius, and moderate $>200 \%$ increases in a middle plume of $288 \pm 63 \mu \mathrm{m}$ radius, and an outer plume of $392 \pm 58$ $\mu \mathrm{m}$ radius of $125 \%$ elevation over control levels (effect of DNQX on plume radius versus vehicle non-laser group: $F_{(1,14)}=7.740$, $p=0.015, d=3.93)$. Optogenetic excitation by itself, or laser illumination of NAc ChR2 neurons with vehicle microinjection, produced an intense inner plume with $>300 \%$ elevation of $38 \pm$ $13 \mu \mathrm{m}$ radius, a middle plume of $206 \pm 49 \mu \mathrm{m}$ radius of $>200 \%$, and an outer plume of $300 \pm 53$ SEM $\mu \mathrm{m}$ radius of $125 \%$ elevation over control levels. Therefore, the diameter of Fos plumes suggested that an aligned fiber tip placed within $<0.5 \mathrm{~mm}$ to $<0.8 \mathrm{~mm}$ of a microinjector tip, would create a zone of overlapping impact for both manipulations on neurons in medial shell.

Adding aligned laser ChR2 stimulation to a DNQX microinjection trended toward shrinking the size of the resulting inner, middle, and outer Fos plumes by $67 \pm 20 \%$ SEM, $31 \pm 22 \%$ SEM, and $18 \pm 18 \%$ SEM, respectively, although variance was high, from sizes produced by DNQX microinjection alone (DNQX alone: inner plume $=94 \pm 51 \mathrm{SEM} \mu \mathrm{m}$, middle plume $=288 \pm$ $63 \mu \mathrm{m}$; outer plume $=392 \pm 58 \mu \mathrm{m}$; combined laser ChR2 + DNQX: inner plume $=31 \pm 19 \mu \mathrm{m}$, middle plume $=200 \pm 63$ $\mu \mathrm{m}$; outer plume $=325+72 \mu \mathrm{m}$; Fig. 1 ). This trend toward reduction nearly reversed the level of laser ChR2 + DNQX local Fos elevation back to vehicle levels after laser excitation alone without DNQX (laser alone: inner plume $=38 \pm 13 \mu \mathrm{m}$, middle plume $=206 \pm 49 \mu \mathrm{m}$; outer plume $=300 \pm 53 \mathrm{SEM} \mu \mathrm{m})$, so that they no longer differed from vehicle plumes $\left(F_{(1,14)}=1.358\right.$, $p=0.263)$. This suggests that laser ChR2 stimulation opposed neurobiological effects of DNQX microinjection that controlled Fos increases in local neurons.

We note DNQX induction of increased local NAc Fos may seem confusing given that DNQX should suppress neuronal firing. However, Fos reflects third-messenger genomic transcrip- 

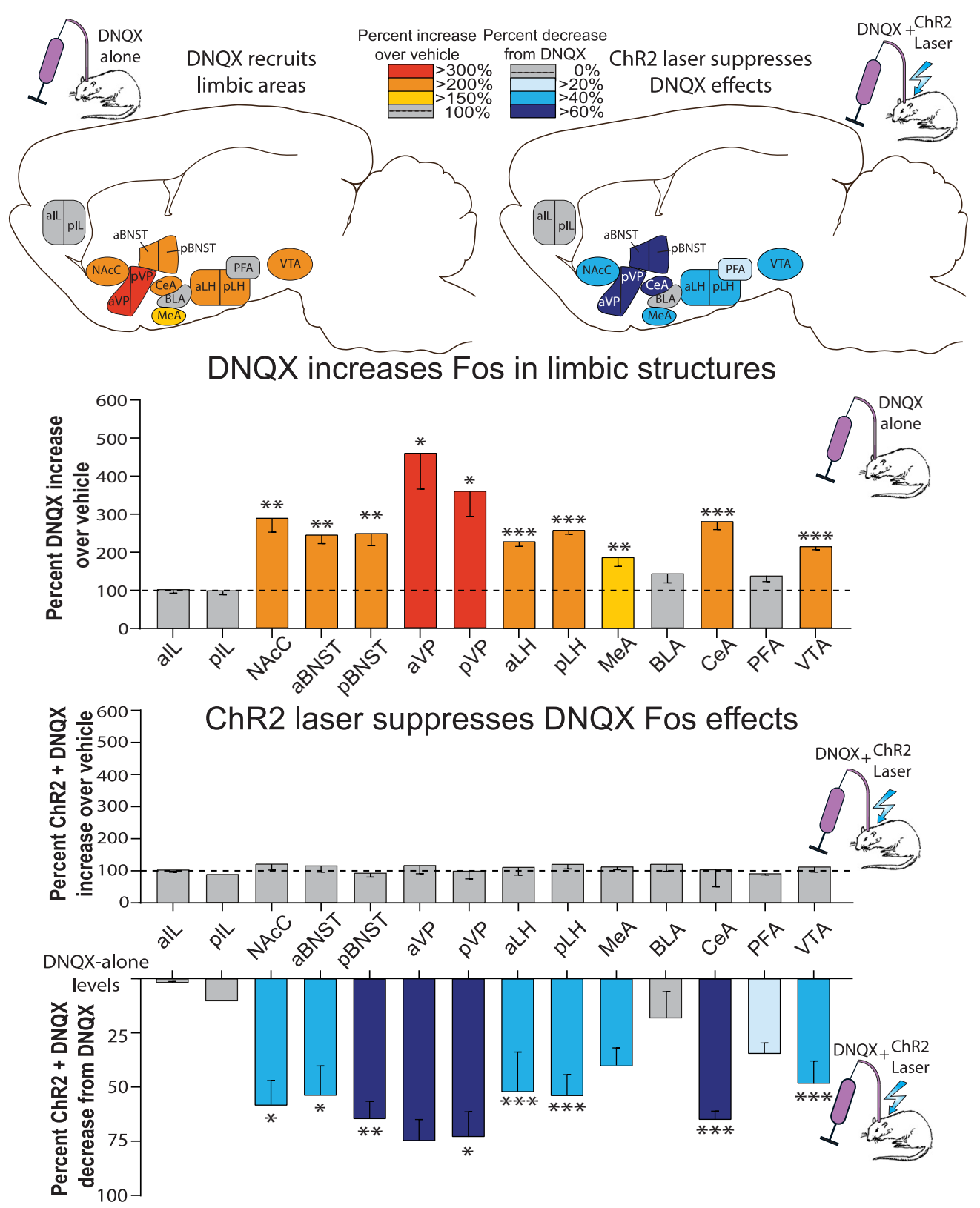

Figure 2. Same-site ChR2 laser reverses distant Fos activation induced by NAC DNQX microinjections. Top, Sagittal brain maps show recruitment of limbic Fos elevations by DNQX microinjections in NAc shell compared with vehicle (left; red/orange). ChR2 laser induced reversals of DNQX-induced Fos is shown as suppressions from DNQX-alone levels (right; blue). Middle, Bar graphs depict the quantitative percentage increase of DNQX-induced Fos elevations in limbic structures over vehicle control levels; dashed line at 100\% = vehicle levels (red/orange bars). Center uncolored bars show Laser + DNQX levels compared with vehicle levels. Bottom, Bars (blue) show suppression of Laser + DNQX levels compared with DNQX-alone levels. ${ }^{*} p<0.05$, ${ }^{* *} p<0.01,{ }^{* * *} p<0.001$.

tion signals, in response in second messenger intra-neuronal signals, and so can depart from electrophysiological activation (Herdegen and Leah, 1998). Whether DNQX-induced Fos reflects changes in receptor signal, or lateral GABAergic disinhibition from suppressed neighboring MSNs, or other factors is unknown. We do not take Fos plumes as a proxy for electrophysiological activation, but merely as a proxy for spread of drug action or spread of laser/ChR2 action on local neurons.

\section{NAc laser reverses DNQX-elicited Fos increases in distant brain structures}

DNQX microinjections by themselves in NAc shell, without laser, also recruited distant increases in Fos expression in several other limbic brain structures distributed across the brain, consistent with the idea of downstream circuitry being released into excita- tion to generate motivated behaviors (Fig. 2). Fos expression was more than doubled by DNQX microinjections in several structures that directly receive NAc shell output projections, such as LH, VP, and VTA compared with control baselines measured in rats that received vehicle microinjection without laser: anterior ventral pallidum $\left(\mathrm{aVP} ; 457 \pm 94 \%\right.$ increase, $t_{(10)}=3.103, p=$ $0.011, d=2.31)$, posterior VP (pVP; $359 \pm 65 \%$ increase, $t_{(9)}=$ $3.269, p=0.010, d=2.36)$, anterior lateral hypothalamus (aLH; $228 \pm 11 \%$ increase, $t_{(9)}=7.381, p<0.001, d=4.44$ ), posterior $\mathrm{LH}\left(\mathrm{pLH} ; 257 \pm 9 \%\right.$ increase, $\left.t_{(11)}=10.872, p<0.001, d=6.03\right)$, and VTA $\left(214 \pm 8 \%\right.$ increase, $\left.t_{(8)}=8.403, p<0.001, d=5.37\right)$. Fos expression was similarly increased by NAc DNQX in structures belonging to the extended amygdala macrosystem: anterior bed nucleus of stria terminalis (aBNST; $245 \pm 23 \%$ increase, $t_{(10)}$ $=4.198, p=0.002, d=2.85$ ), posterior BNST (pBNST; $250 \pm$ 
$29 \%$ increase, $\left.t_{(10)}=4.046, p=0.002, d=2.67\right)$, medial amygdala $\left(\mathrm{MeA} ; 186 \pm 24 \%\right.$ increase, $t_{(11)}=3.200, p=0.008$, $d=2.07$ ), central amygdala (CeA; $281 \pm 20 \%$ increase, $t_{(10)}=$ $5.872, p<0.001, d=3.40)$. Finally, NAc shell DNQX increased in another NAc component, the core (NAcC; $288 \pm 36 \%$ increase, $\left.t_{(9)}=3.769, p=0.004, d=3.19\right)$. However, trends toward increases did not reach statistical significance in several other structures: in anterior infralimbic cortex (aIF; $101 \pm 9 \%$ increase, $t_{(10)}$ $=0.046, p=0.964$ ), posterior infralimbic cortex (pIF; $103 \pm$ $11 \%$ increase, $\left.t_{(10)}=0.122, p=0.906\right)$, basolateral amygdala (BLA; $144 \pm 24 \%$ increase, $t_{(10)}=0.850, p=0.415$ ), or perifornical hypothalamus (PFA; $136 \pm 15 \%$ increase, $t_{(11)}=1.766, p=$ 0.105; Fig. 2).

Adding aligned laser illumination in ChR2 rats to DNQX microinjections in NAc shell also successfully attenuated the recruitment of increases in distant Fos expression over vehicle control levels in most structures listed. Accordingly, ChR2 rats that had aligned NAc shell laser illumination plus DNQX microinjections had significantly lower Fos in several limbic structures than ChR2 rats that received DNQX microinjections alone: DNQX-induced Fos was suppressed by ChR2 laser illumination in direct target subregions of VP, LH, and VTA: pVP (73 \pm $7 \%$ suppression, $\left.t_{(7)}=2.696, p=0.031, d=2.59\right)$, aLH (52 \pm $11 \%$ suppression, $\left.t_{(7)}=5.274, p=0.001, d=3.46\right), \mathrm{pLH}$ (54 $\pm 6 \%$ suppression, $\left.t_{(8)}=8.070, p<0.001, d=5.58\right)$, and VTA ( $48 \pm 7 \%$ suppression, $t_{(6)}=6.091, p=0.001, d=4.81$ ). DNQX-induced Fos was similarly suppressed by ChR2 laser illumination in extended amygdala structures: aBNST $(54 \pm 8 \%$ suppression, $\left.t_{(8)}=2.878, p=0.021, d=2.37\right)$, pBNST $(63 \pm 5 \%$ : $\left.t_{(8)}=3.411, p=0.009, d=3.23\right)$, CeA $(65 \pm 18 \%$ suppression, $\left.t_{(7)}=5.719, p=0.001, d=4.39\right)$. Finally, DNQX-induced Fos was also suppressed by ChR2 laser illumination in the core of NAc (NAcC $58 \pm 7 \%$ suppression from DNQX alone: $t_{(8)}=$ $2.871, p=0.021, d=2.63)$. However, no significant suppression was found in aVP or MeA, though there was a trend in this direction (aVP: $75 \pm 6 \%$ suppression, $t_{(8)}=2.281, p=0.052, d=2.33$; MeA: $40 \pm 5 \%$ suppression, $\left.t_{(8)}=1.976, p=0.084, d=1.93\right)$. Similarly, there was no laser-induced change in structures that did not show a DNQX-recruited enhancement in Fos such as aIF ( $1 \pm 2 \%$ suppression, $\left.t_{(6)}=0.079, p=0.940\right)$, pIF ( $11 \%$ suppression, $\left.t_{(5)}=0.285, p=0.787\right)$, BLA (18 $\pm 12 \%$ suppression, $t_{(7)}=$ $0.634, p=0.546)$, and PFA (34 $\pm 3 \%$ suppression, $t_{(8)}, p=$ $0.110)$

One ChR2 rat that received DNQX with laser illumination had only a unilateral NAc cannula aligned with fiber optic (with contralateral cannulae in ventral pallidum). Nonetheless, this rat demonstrated a similar laser-induced attenuation of distant Fos activation compared with rats that received DNQX alone: aVP (70\% suppression), pVP (66\% suppression), aLH (30\% suppression), pLH (43\% suppression), VTA (56\% suppression), aBNST (47\% suppression), pBNST (59\% suppression), CeA (54\% suppression), and NAcC (68\% suppression).

By contrast with ChR2 rats, laser was ineffective in control rats with inactive eYFP virus in altering DNQX-elicited Fos levels, at all sampled structures throughout the brain: eYFP rats that received DNQX plus laser did not differ from eYFP rats that received DNQX alone without laser (aVP: $t_{(7)}=0.988, p=0.356$; pVP: $t_{(6)}=1.183, p=0.282$; aLH: $t_{(6)}=0.988, p=0.361$; pLH: $t_{(7)}=4.745, p=0.201$; VTA: $t_{(5)}=0.721, p=0.503$; aBNST: $t_{(7)}$ $=0.723, p=0.493$; pBNST: $t_{(7)}=0.254, p=0.806$; MeA: $t_{(7)}=$ $0.835, p=0.431$; CeA: $t_{(6)}=1.028, p=0.344$; NAcC: $t_{(7)}=1.877$, $p=0.103$; aIF: $t_{(5)}=1.524, p=0.188$; pIF: $t_{(5)}=0.007, p=0.995$; BLA: $t_{(6)}=0.562, p=0.594$; PFA: $\left.t_{(7)} 1.223, p=0.261\right)$.
ChR2 rats that received laser alone in NAc, with vehicle but not DNQX microinjections, trended toward Fos changes in distant brain structures, but these did not reach statistical significance given the few subjects in this group $(n=3)$. That is, ChR2 rats that received NAc laser plus vehicle microinjections aVP (20 $\pm 59 \%$ suppression below vehicle microinjections alone, $t_{(7)}$ $=1.117, p=0.301), \mathrm{pVP}\left(138 \pm 72 \%\right.$ enhancement, $t_{(6)}=1.183$, $p=0.282)$, aLH $\left(132 \pm 52 \%\right.$ enhancement, $t_{(5)}=0.918, p=$ $0.401), \mathrm{pLH}\left(147 \pm 32 \%\right.$ enhancement, $\left.t_{(7)}=2.354, p=0.051\right)$, VTA $\left(106 \pm 48 \%\right.$ enhancement, $\left.t_{(4)}=0.207, p=0.846\right)$, aBNST $\left(132 \pm 93 \%\right.$ enhancement, $\left.t_{(5)}=0.620, p=0.563\right)$, pBNST $\left(104 \pm 38 \%\right.$ enhancement, $\left.t_{(6)}=0.119, p=0.909\right)$, MeA $(145 \pm$ $40 \%$ enhancement, $\left.t_{(7)}=1.558, p=0.163\right)$, CeA $(132 \pm 90 \%$ enhancement, $\left.t_{(7)}=0.583, p=0.578\right)$, NAcC ( $141 \pm 51 \%$ enhancement, $\left.t_{(5)}=0.782, p=0.470\right)$, aIF (102\% enhancement, $\left.t_{(5)}=1.027, p=0.351\right), \operatorname{pIF}$ ( $8 \%$ suppression, $t_{(5)}=1.034, p=$ $0.349)$, BLA ( $144 \pm 21 \%$ enhancement, $\left.t_{(7)}=1.221, p=0.262\right)$, PFA $\left(103 \pm 19 \%\right.$ enhancement, $\left.t_{(7)}=0.114, p=0.912\right)$. We note that other studies have reported distant increases in Fos in VP, $\mathrm{LH}$, and VTA to be induced by ChR2 stimulation of NAc MSN populations (Cole et al., 2018; Soares-Cunha et al., 2018).

\section{Behavioral effects: DNQX in shell increased food intake in standard laboratory environment}

Overall, DNQX microinjections in NAc shell increased food intake measured as grams consumed and similarly increased cumulative time spent eating (two-way ANOVA main effect of drug on food intake: $F_{(1,13)}=30.857, p<0.001$; two-way ANOVA main effect of drug on time spent eating: $F_{(1,13)}=28.665, p<0.001$; Figs. 3, 4). Anatomical comparison of rostral versus caudal sites of DNQX microinjection in medial shell produced similar increases in food in a standard laboratory environment here, and the anatomical halves did not differ in magnitude of eating increase (ANOVA drug $\times$ laser conditions by anatomical placement on food intake: $F_{(1,12)}=0.742, p=0.406$; on time spent eating: $F_{(1,12)}=0.185, p=0.675$; on eating bouts: $F_{(1,12)}=0.421$, $p=0.529)$.

Overall here, DNQX microinjections in NAc shell caused rats to increase food consumption $>300 \%$ compared with vehicle microinjection baselines in the same rats (grams of chow eaten $1.5 \pm 0.4 \mathrm{~g}$ after vehicle; $4.8 \pm 0.5 \mathrm{~g}$ after DNQX; $t_{(13)}=5.464$, $p<0.001$, Cohen's $d=1.46$; Fig. 3 ), a result consistent with many previous studies with DNQX sites mostly in rostral shell (Maldonado-Irizarry et al., 1995; Reynolds and Berridge, 2003, 2008; Faure et al., 2010; Richard and Berridge, 2011; Richard et al., 2013; Fig. 4). In behavioral duration of eating bouts, DNQX microinjections also increased bout duration by $>250 \%$ relative to vehicle baselines (mean DNQX/no laser: $480.0 \pm 67.2 \mathrm{~s}$ in the hour-long session; vehicle/no laser: $181.6 \pm 51.3 \mathrm{~s} ; t_{(13)}=4.70$, $p=0.001, d=1.26)$. A bout was defined as continuous eating with no pause for at least $0.5 \mathrm{~s}$, separated from other bouts by pauses of $>0.5 \mathrm{~s}$. DNQX similarly increased the number or frequency of emitted eating bouts by $>250 \%\left(t_{(13)}=3.02, p=\right.$ $0.010, d=0.81)$.

\section{Same-site optogenetic stimulation reversed DNQX increases in food intake}

Adding laser ChR2 excitation reversed the ability of DNQX microinjections in medial shell to cause increases in food intake, at least for rats with bilaterally aligned fiber and cannula tips at the same NAc site (i.e., both within $1 \mathrm{~mm}$ of microinjector tip; $t_{(13)}=$ $2.771, p=0.016, d=0.74$; Figs. 3,7$)$. Rats with bilaterally aligned fiber/cannula tips consumed $5.5 \pm 0.6 \mathrm{~g}$ after DNQX microinjec- 


\section{Standard environment}

Within subjects group

ChR2 laser blocks DNQX-eating

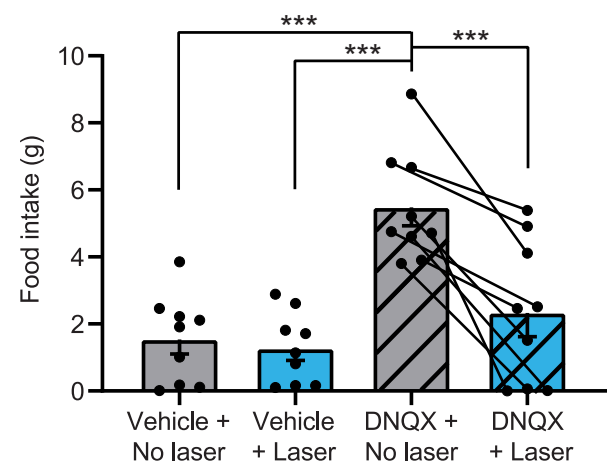

Between subjects group

ChR2 laser blocks DNQX-eating

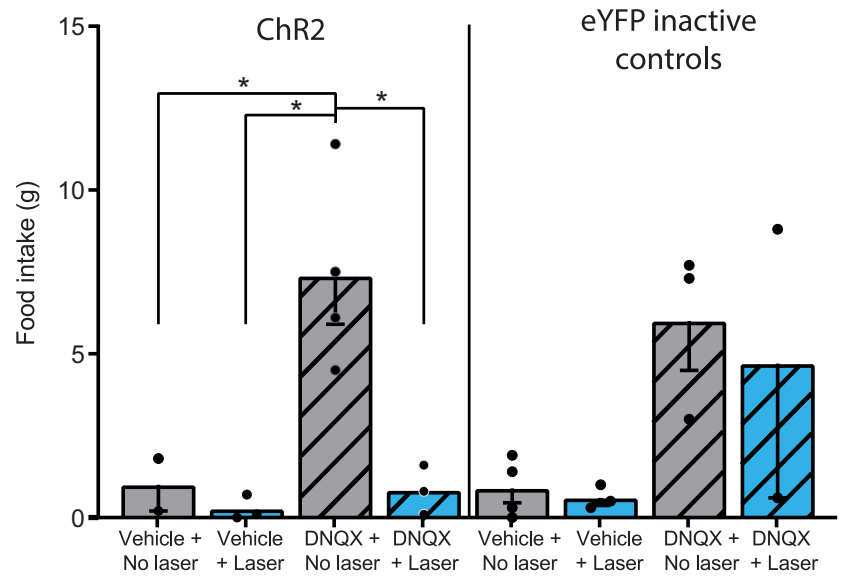

Figure 3. Aligned ChR2 laser reverses DNQX increases in food intake. DNQX microinjections alone without laser caused increases in food intake for both the within-subjects Group 1 (top) and between-subjects Group 2 (bottom) for NAc shell sites in standard laboratory conditions. Aligned laser illumination in ChR2 rats $(<1 \mathrm{~mm}$ apart) reduced DNQX levels of intake by $\sim 50 \%$, reducing intake to baseline vehicle levels (top). Laser illumination had no effect on vehicle or DNQX intake in control rats with inactive eYFP virus (bottom right). Gray bars alone, no laser vehicle; blue bars alone, laser alone; gray bars with stripes, DNQX alone; blue bars with stripes, DNQX+laser. ${ }^{*} p<0.05,{ }^{* * *} p<0.001$.

tion alone, but adding laser ChR2 stimulation to DNQX cut in half their intake to only $2.3 \pm 0.7 \mathrm{~g}\left(t_{(8)}=6.57, p<0.001, d=\right.$ 2.19). This reduced level of intake after combining ChR2 laser illumination with DNQX no longer differed significantly from control baseline levels of the same rats after vehicle microinjection alone without laser $(\mathrm{DNQX}+$ laser $=2.3 \mathrm{~g}$; vehicle $=1.5 \mathrm{~g}$; $\left.t_{(8)}=1.05, p=0.325\right)$. Behaviorally, adding ChR2 laserstimulation to DNQX correspondingly reduced cumulative duration of time spent eating by $40 \%$ in rats with bilaterally aligned placement $\left(t_{(8)}=2.77, p=0.024, d=0.92\right)$. However, this laserinduced reduction in time spent eating was only partial, as there was still a marginal trend toward more time eating after laser + DNQX combination (mean: $333.0 \pm 90.5 \mathrm{~s}$ ) than after vehicle microinjection without laser (mean: $168.9 \pm 52.5 \mathrm{~s} ; t_{(8)}=2.23$, $p=0.056)$. Similarly, adding ChR2 laser stimulation to DNQX sites did not significantly decrease the number of eating bouts
(DNQX/no laser vs DNQX/laser on number of eating bouts: $t_{(8)}$ $=1.29, p=0.234$ ), though the number of eating bouts also no longer differed between DNQX + laser stimulation and control vehicle baselines or $\left(t_{(8)}=0.646, p=0.536\right)$.

The $5 \mathrm{~s}$ laser ON, $15 \mathrm{~s}$ OFF cycle was repeated throughout the $1 \mathrm{~h}$ test, but we did not see differences in behaviors during the $\mathrm{ON}$ portions versus OFF portions of the cycle (normalized eating laser ON: $528.7 \pm 290.5 \mathrm{~s}$ ) versus laser OFF (462.9 $\pm 221.4 \mathrm{~s} ; t_{(2)}$ $=0.939, p=0.447)$. This suggests that behavioral suppression of DNQX is not tightly time-linked on the order of single seconds. In other words, $5 \mathrm{~s}$ laser ON bins appeared to exert a depressive effect on DNQX behaviors even during the $15 \mathrm{~s}$ period of laser $\mathrm{OFF}$, at least as long as the ON/OFF bins were continuously cycled.

\section{Separation $>1 \mathrm{~mm}$ between tips renders laser impotent to} reverse DNQX eating increase

A separate subgroup of five rats had bilaterally nonaligned sites, with fiber tips and cannulae tips spaced $>1 \mathrm{~mm}$ apart (no rats in this group had a unilaterally aligned site but contralaterally nonaligned site). In bilaterally nonaligned rats, addition of ChR2 laser stimulation failed to reduce at all the DNQX-elevation of food intake (DNQX/laser: $4.3 \pm 1.0 \mathrm{~g}$; DNQX alone: $3.5 \pm 0.9 \mathrm{~g}$; $t_{(4)}=1.68, p=0.168$; see Fig. 7). Similarly, in time spent eating, adding laser to DNQX failed to impede the amount of eating behavior in bilaterally nonaligned rats $\left(t_{(4)}=1.87, p=0.135\right)$. Thus, spatial separation of the optic fiber tip from microinjector cannula tip by a distance $>1 \mathrm{~mm}$ appeared to render optogenetic excitation ineffective, so that ChR2 laser was no longer able to counteract DNQX-induced increases in eating behavior or food intake. This need for $<1 \mathrm{~mm}$ proximity suggests that laser must excite ChR2 neurons in a location that anatomically overlaps with that directly impacted by DNQX in order reverse behavioral effects of the NAc drug, a conclusion supported by Fos plume analyses above. Consistent with the conclusion that NAc ChR2 excitation per se was not a strong suppressor of intake, ChR2 laser stimulation on its own (i.e., after vehicle microinjection) did not suppress chow consumption below baseline levels after vehicle alone here (bilaterally aligned group: $t_{(8)}=0.607, p=0.561$; bilaterally nonaligned $\left.t_{(4)}=0.005, p=0.996\right)$.

We note that the homogenous appetitive pattern for NAc DNQX microinjections at all sites in medial shell was different from our previous studies, which found DNQX at caudal sites typically suppressed food intake in a standard laboratory and instead generated active-coping fearful reactions, such as defensive burying (Reynolds and Berridge, 2001, 2008; Richard and Berridge, 2011, 2013). Here, by contrast, few defensive behaviors were observed under any conditions, although we note that 11 of 14 rats here had sites in rostral shell, and only 3 rats had caudal sites. Thus, DNQX versus vehicle conditions did not differ $\left(F_{(1,12)}\right.$ $=0.352 ; p=0.564)$, nor did rostral and caudal halves differ significantly $\left(F_{(1,12)}=0.058 ; p=0.814\right)$. For this reason, and because DNQX produced similar increases in food intake in the three rats with caudal sites as in the larger rostral group, subsequent analyses of laser and DNQX effects on food intake combined all sites together.

\section{Single-test between-subject group local ChR2 laser reverses DNQX-stimulation of eating}

In the bilaterally-aligned ChR2 rats of Group 2 (between-subjects comparison), each rat was behaviorally tested only in one of the four microinjection/laser conditions (balanced across different rats: vehicle-no laser; DNQX-no laser; DNQX-laser; vehicle- 


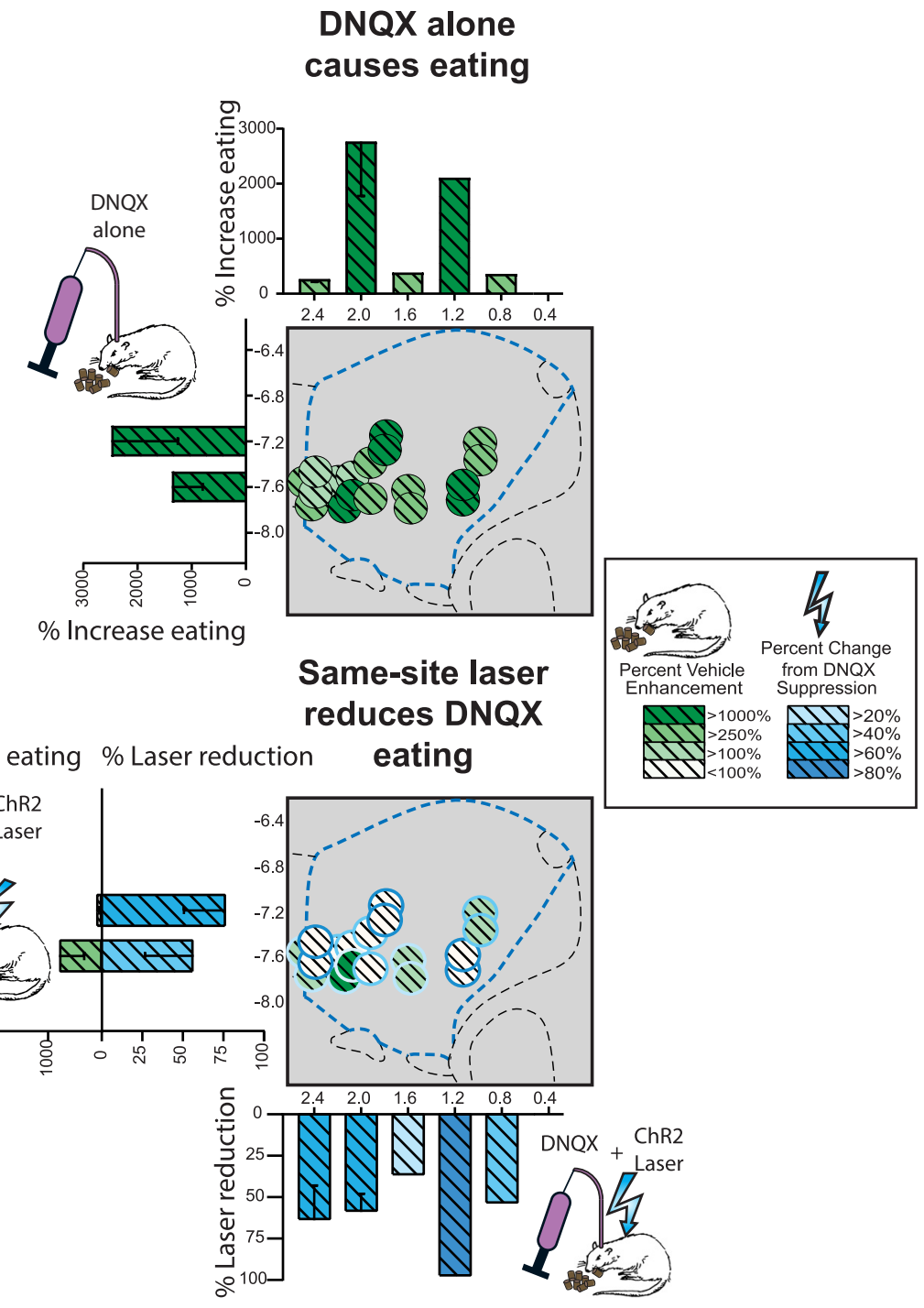

Figure 4. NAc site maps of intake increases induced by DNQX microinjections and reversals induced by adding laser. Top, Sagittal placements show percentage changes in food intake change from vehicle baseline induced by DNQX microinjections alone (green) in standard laboratory conditions for within-subjects Group 1. Bottom, Percentage suppressions of intake from DNQX levels induced by adding aligned laser illumination (blue).

laser), and then immediately killed for Fos processing afterward. In this group, DNQX similarly elicited appetitive increases in intake when tested in a standard laboratory environment, and ChR2 laser stimulation at the same site similarly reversed DNQXinduced increases in appetitive motivation (Fig. 3). Although a between-subjects comparison might be less sensitive than a within-subjects comparison, most effects described above were reproduced here. Rats with NAc DNQX microinjections alone ate more grams of food than rats that received vehicle microinjections alone (main effect of drug on intake: $F_{(1,5)}=66.517, p<$ $0.001)$. Again as in the within-subjects comparison, rats with DNQX-alone sites in either rostral or caudal halves of medial shell had higher food intakes than rats with corresponding vehicle-alone sites, and rostral and caudal halves did not differ in magnitude of intake enhancement (main effect of site: $F_{(1,5)}=$ 3.755, $p<0.110$; site $\times$ valence interaction: $F_{(1,5)}=3.755, p<$ $0.110)$. Similarly, no defensive behavior was elicited at any site. For these reasons, rostral and caudal sites were again combined for subsequent statistical analyses of laser modulating effects on feeding behavior.
Combined, rats that received DNQX microinjections without laser ate $>700 \%$ more chow than rats that received vehicle microinjections without laser (DNQX: $7.4 \pm 1.5$ g; vehicle: $1.0 \pm 0.8 \mathrm{~g}, p=0.028$, $d=3.14$ ). DNQX rats without laser similarly ate more than rats that received vehicle microinjections with laser $(0.3 \pm 0.2 \mathrm{~g}$, $p=0.007, d=4.27$ )

Adding concurrent laser ChR2 stimulation during test reduced the magnitude of food intake elicited by DNQX microinjections back to vehicle baseline levels, so that intake did not differ from that of control rats that received vehicle (without laser; $1.0 \pm 0.8$ g. $p>0.05$ ). Thus, intake of ChR2 rats with DNQX plus simultaneous laser illumination was only $\sim 10 \%$ of intake levels of ChR2 rats that received DNQX alone (without laser; ChR2 DNQX alone $=7.4 \pm 1.5 \mathrm{~g}$; ChR2 DNQX + laser $=0.8 \pm 0.4 \mathrm{~g}$; main effect of drug $=F_{(1,8)}=9.448, p=0.015$; main effect of laser $=F_{(1,8)}=10.377, p=0.012$; drug $\times$ laser interaction $=F_{(1,8)}=6.615$, $p=0.033)$. ChR2 rats that received vehicle microinjections plus laser illumination ate the lowest amount of all $(0.3 \pm 0.2 \mathrm{~g})$, consistent with a main suppressive effect of laser, but this did not differ statistically from the $\sim 1 \mathrm{~g}$ amounts eaten by vehicle eYFP control rats.

Among rats with bilaterally aligned optic fiber tips and DNQX microinjection tips ( $n=19$ of 24 ), those that concurrently received additional ChR2 laser excitation combined with DNQX ate far less chow $(0.8 \pm 0.4 \mathrm{~g})$ than those that received DNQX microinjections alone without laser $(7.4 \pm 1.5 \mathrm{~g} ; p=0.012, d=$ 3.54). The intake level of the rats with combined aligned ChR2 laser stimulation plus DNQX microinjection did not differ from control baseline intake levels of rats that received vehicle microinjections alone without laser $(p>0.05)$. Similarly, in terms of behavioral time spent eating, ChR2 rats that received DNQX microinjections alone spent $896 \pm 282 \mathrm{~s}$ in cumulative duration of eating, whereas eating duration of ChR2 rats that had laser illumination added to DNQX microinjection was $\sim$ onehalf that amount, $374 \pm 299 \mathrm{~s}$, though these were not statistically different $\left(t_{(6)}=1.27, p=0.250\right)$. By comparison, ChR2 rats that received vehicle microinjections alone spent only $154 \pm 117 \mathrm{~s}$ engaging in eating, and ChR2 rats that received laser illumination added to vehicle microinjections trended toward reducing further to only $33 \pm 30 \mathrm{~s}\left(t_{(3)}=1.258, p=0.298\right)$.

One ChR2 rat that received DNQX with laser illumination had only a unilateral NAc cannula aligned with fiber optic tip, whereas the contralateral cannula missed the NAc shell entirely and was in ventral pallidum (Table 3). This DNQX + laser rat with unilateral NAc shell cannula and ChR2 virus displayed nearly equivalent levels of laser-induced suppression DNQXelicited feeding relative to rats that received DNQX with laser excitation with bilateral ChR2 expression (78 vs $94 \pm 5 \%, p=$ 
Table 3. Between-subjects alignment of fiber/cannula tips for ChR2 animals only

\begin{tabular}{|c|c|c|c|c|c|c|c|}
\hline $\begin{array}{l}\text { Test } \\
\text { environment }\end{array}$ & Placement & Cannulae & Fiber & $N$ & $\begin{array}{l}\text { DNQX increase, \% } \\
\text { (vs vehicle group) }\end{array}$ & $\begin{array}{l}\text { Laser suppression, \% } \\
\text { (vs DNQX only group) }\end{array}$ & $\begin{array}{l}\text { Missed } \\
\text { target }\end{array}$ \\
\hline \multirow[t]{6}{*}{ Standard (Fos) } & All combined & Bilateral & Bilateral aligned & 7 & 1488 & 94 & - \\
\hline & & & Unilateral aligned & 0 & - & - & - \\
\hline & & & Misaligned & 0 & - & - & - \\
\hline & & & Unilateral virus & 3 & 804 & - & - \\
\hline & & Unilateral & Unilateral aligned & 2 & - & 78 & VP;MS \\
\hline & & & Misaligned & 0 & - & - & - \\
\hline
\end{tabular}

In the current study, ChR2 laser reversed DNQX effects even in rats with aligned fiber-cannula tips on only one side of NAc fiber. MS, Medial septum.

0.221). All other rats in the betweensubject group had bilaterally aligned fiber and cannula tips (i.e., $<1.0 \mathrm{~mm}$ separation between optic fiber tip and microinjector tip).

Control rats with optically-inactive eYFP virus that received DNQX microinjections similarly ate more than rats that received vehicle microinjections alone (DNQX: $5.5 \pm 1.6 \mathrm{~g}$; vehicle: $0.7 \pm 0.3 \mathrm{~g}$; main effect of drug: $F_{(1,8)}=9.582, p=$ $0.015)$. However, laser illumination did not reduce the DNQX-induced increases in intake in eYFP rats, which remained comparable to intake of eYFP rats that received DNQX alone $\left(F_{(1,8)}=0.113, p=\right.$ $0.745)$. Similarly, laser illumination of the NAc shell did not impact intake in eYFP rats (no laser: $3.1 \pm 1.2 \mathrm{~g}$, laser: $2.2 \pm$ $1.6 \mathrm{~g}$; main effect of laser: $F_{(1,8)}=0.290$, $p=0.605)$.

\section{Stressful environment: within-subject group: ChR2 laser reverses caudal DNQX-induced 'fear' as well as rostral 'desire'}

Why caudal DNQX sites produced more appetitive eating and less defensive treading/burying than in our earlier studies remains unknown, but suggests a more positive bias in affective valence in our current rats. As potential contributing factors, we note that rats in the present study had a history of greater environmental enrichment in rearing and housing conditions than rats in previous studies in our laboratory roughly (e.g., more toys, climbing features, and related environmental enrichment are now provided in home cages than was typical in earlier years), and also were group housed throughout their lives, ensuring social interactions. Possibly having enriched and social environments encourages a more positive valence bias in rats. Alternatively, genetic drift across generations may have altered affective dispositions, or the change could be due to other unknown causes.

In any case, the relatively positive affective bias here prompted us to repeat the within-subject experiment here, but using Long-Evans rats $(n=11)$, which may be more emotionally reactive than Sprague-Dawley rats, and imposing a moderately stressful environment. A stressfully louder and brighter environment has been found to facilitate the induction of negatively-valenced fearful behaviors by DNQX microinjections in NAc medial shell (Reynolds and Berridge, 2008; Richard and Berridge, 2011). Inducing fearful defensive

\section{Stressful environment}

ChR2 laser blocks caudal NAc DNQX-fear

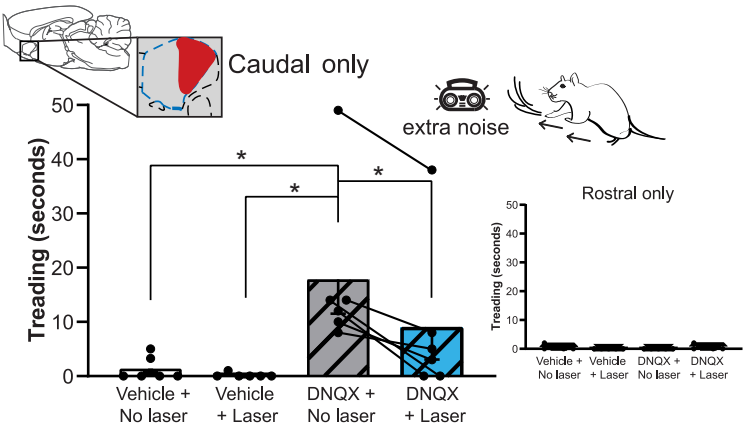

ChR2 laser blocks rostral NAc DNQX-eating
Treading directed to front of test chamber

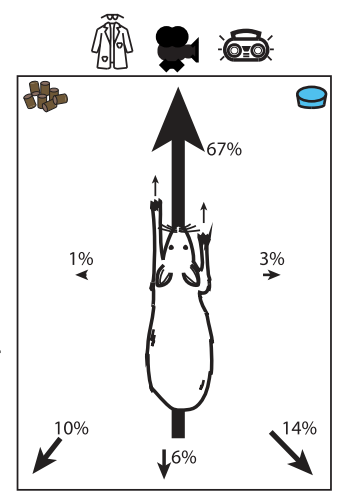

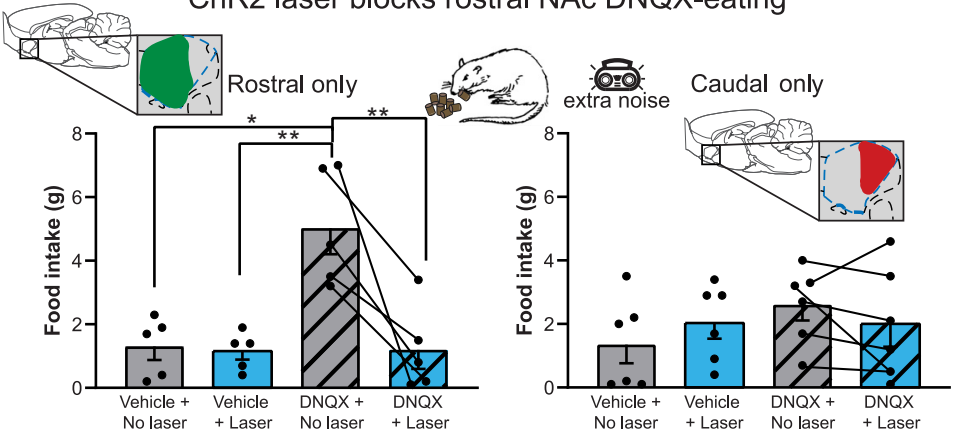

Figure 5. ChR2 laser reverses caudal 'fear' as well as rostral 'desire' induced by DNQX microinjections. At caudal sites in NAc shell DNQX microinjections alone elicited defensive treading-burying behavior when ChR2 rats were tested in a stressfully loud envi(top right). Adding aligned laser illumination substantially reversed DNQX ability to elicit defensive behavior at caudal sites. At ostral sites, DNQX elicited increases in food intake in the loud environment (bottom left). Laser illumination again reversed appetitive intake elicited by DNQX at rostral sites. ${ }^{*} p<0.05,{ }^{* *} p<0.01$.

treading-burying, a natural rodent anti-predator reaction, by NAc DNQX microinjections in rats tested in a stressfully loud environment therefore allowed us to assess if aligned ChR2 laser illumination in medial shell reverses defensive motivation, just as it reversed appetitive motivation in the standard environment experiments.

Results showed that, as expected in the stressfully loud environment, NAc DNQX microinjections without laser at caudal sites in medial shell (defined as $<+1.2 \mathrm{~mm}$ anterior to bregma; $n=6$ ), elicited negatively-valenced defensive treading-burying behavior (two-way repeated-measures ANOVA, valence $\times$ site interaction: $F_{(1,9)}=5.359, p=0.046$; Figs. 5, 6). Defensive treading-burying consisted of rhythmic forward and backward thrusts of the forepaws $(1-3 \mathrm{~cm}$ extension) with paw palm oriented forward. The treading-burying movements served to kick granules of corncob bedding forward in front of the rat, which if sufficiently persistent and appropriately directed, can form an elevated mound as barrier between the rat and a perceived threat, 

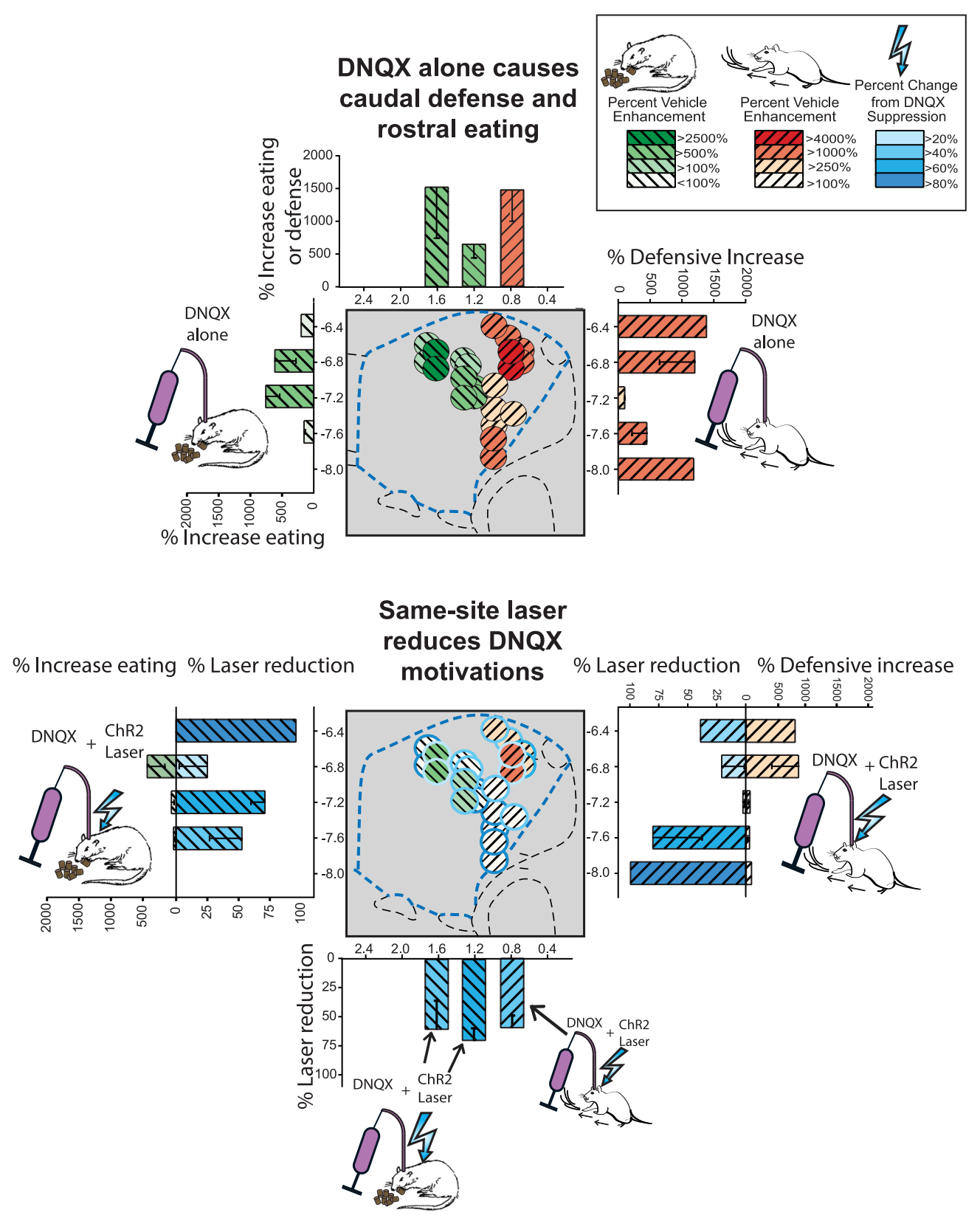

Figure 6. NAc site maps of DNQX-induced caudal 'fear' and rostral 'desire', and reversals induced by same-site laser. Top, Sagittal placements show percentage increases in defensive behavior (orange) and in appetitive behavior (green) induced at sites in NAc shell by DNQX microinjections alone in the loud environment. Bottom, Placements show suppressions from DNQX levels (blue) of motivated behavior induced by adding aligned laser illumination in the same ChR2 rats.

and sometimes even bury a threatening object (Treit et al., 1981; Reynolds and Berridge, 2001).

\section{Lack of sex differences in DNQX + laser effects}

Overall, females with caudal DNQX placements tended to emit more defensive treading/burying (mean: $10.7 \pm 3.9 \mathrm{~s}$ ) than males (mean: $3.5 \pm 3.9 \mathrm{~s}$ ), although this sex difference was not significant given the small sample size $\left(F_{(1,4)}=1.665, p=0.226\right)$. However, females and males showed equal percentage levels of laser-induced ChR2 reduction of treading in the DNQX + laser condition (females: $49 \%$ reduction from DNQX-alone; mean: $12.4 \pm 12.2 \mathrm{~s}$; males: $62 \%$ reduction from DNQX-alone: $4.3 \pm$ $\left.2.3 ; F_{(1,4)}=0.736, p=0.439\right)$.

For rats with rostral NAc sites, males tended to eat more at baseline and after DNQX (baseline: $2.4 \pm 0.4 \mathrm{~g}$; DNQX: $5.8 \pm$
$1.2 \mathrm{~g}$ ) than females (baseline: $1.8 \pm 0.5$; DNQX; $3.9 \pm 0.7 \mathrm{~g}$ ), though this was not significant for the current sample $\left(F_{(1,3)}=\right.$ $4.97, p=0.112$ ). However, females and males showed equal percentage levels of laser-induced ChR2 reduction of food intake from the DNQX-alone condition (males: $71 \%$ reduction from DNQX-alone; mean: $1.7 \pm 1.0$ g; females: $87 \%$ reduction from DNQX-alone; $0.5 \pm 0.3 \mathrm{~g}$ ). For these reasons, males and females were combined for subsequent statistical analyses of the effects of DNQX on appetitive versus defensive behavior, and for the modulating effects of adding laser to DNQX.

\section{Anatomical segregation of DNQX motivational valence:} rostral 'desire' versus caudal 'fear'

Here, the three rats with unilateral tips $<0.5 \mathrm{~mm}$ apart and contralateral tips between $0.5-0.8 \mathrm{~mm}$ apart showed levels of laser- 
induced suppressions of eating that were similar to suppression levels of rats with bilateral $<0.5 \mathrm{~mm}$ placements (unilateral $=93.8 \%$ reduction; bilateral $=$ $72.2 \pm 11.1 \%$ reduction). Unilaterally $<0.5 \mathrm{~mm}$ aligned rats with sites in caudal shell $(n=2)$ also showed similar levels of laser-induced suppressions of defensive behavior as bilaterally aligned rats (unilateral $<0.5 \mathrm{~mm}=56.4 \pm 13.6 \%$; bilateral $<0.5 \mathrm{~mm}=65.0 \pm 20.4 \%$ ). Therefore, unilaterally-aligned and bilaterally-aligned groups were combined in subsequent statistical analyses.

Defensive treading-burying behavior was elicited by DNQX alone in the loud environment only at sites in the caudal half of NAc shell, and never at rostral sites (Kruskal-Wallis test: $\chi^{2}: 15.225, p=$ 0.002; Figs. 5, 6). Defensive treadingburying was oriented typically $(67 \%)$ to throw cob bedding forward specifically toward the front of the transparent chamber facing the open room, which was relatively bright and where the human experimenter occasionally moved. DNQX alone at caudal sites increased fearful treading-burying behavior $>750 \%$ over vehicle/no laser control levels in the same rats (DNQX cumulative time spent treading: $17.8 \pm 6.3$ s per session; vehicle: $1.3 \pm$ 0.9 s; Wilcoxon: $Z=2.201, p=0.028, r=$ 0.90). Similarly, DNQX at caudal sites caused a $>500 \%$ increase in the number of discrete bouts of defensive treadingburying over vehicle control levels of the same rats (bout $=$ continuous treading-burying with no pause $>0.5 \mathrm{~s}$; DNQX bout number: $7.0 \pm 1.0$; vehicle: $1.3 \pm 0.9 ; t_{(10)}=3.96, p=0.011, d=$ 1.62). The same caudal DNQX microinjections without laser did not increase food intake in the stressful environment $\left(t_{(5)}=1.97, p=0.106\right)$.

Conversely, at rostral sites in medial shell $(>+1.2 \mathrm{~mm}$ bregma; $n=5$ ), DNQX microinjections alone elicited $400 \%$ increases in food intake above vehicle baseline levels of the same rats, similar to groups above (DNQX: $5.0 \pm 1.8 \mathrm{~g}$; vehicle/no laser: $1.3 \pm$ $\left.0.9 \mathrm{~g} ; t_{(4)}=3.83, p=0.019, d=1.71\right)$, and $>300 \%$ increases in time spent eating (DNQX: $635.8 \pm 125.0 \mathrm{~s}$; vehicle: $191.6 \pm$ $\left.73.3 \mathrm{~s} ; t_{(4)}=3.004, p=0.040, d=1.34\right)$. Anatomically, all appetitive eating increases were produced only by sites in the rostral half of medial shell in this stressfully loud environment $\left(t_{(9)}=\right.$ 2.642, $p=0.027, d=1.60)$. We note that one ChR2 rat had a unilateral microinjection site in the rostral shell, with the contralateral cannula in the bed nucleus of stria terminalis. Its unilateral DNQX NAc microinjection still caused an $>800 \%$ increase in food intake; however, because it was only a unilateral NAc site, this rat was considered separately in the analysis of laser modulation effects.

\section{Simultaneous laser ChR2 stimulation reversed} DNQX-induced caudal 'fear' and rostral 'desire'

In ChR2 rats with aligned fiber-cannula tips at caudal sites in the medial shell, adding laser illumination reduced DNQX-elicited the amount of defensive behavior to $\sim 50 \%$ compared with levels of the same rats after DNQX-alone (DNQX + laser: $9.0 \pm 5.9 \mathrm{~s}$ cumulative duration; DNQX alone: $17.8 \pm 6.3 \mathrm{~s}$; Wilcoxon: $Z=$ 2.201, $p=0.028, r=0.90$; caudal vs rostral sites: Kruskal-Wallis test: $\left.\chi^{2}: 14.425, p=0.002\right)$. Levels of defensive behavior after combined laser + DNQX microinjection at caudal sites no longer statistically differed from control baseline levels measured after vehicle microinjections in the same rats, although still trending to remain nominally higher, suggesting at least a partial reversal that was very substantial (laser + DNQX mean: $9.0 \pm 5.9$; vehicle mean: $1.3 \pm 0.9$; Wilcoxon: $Z=1.214, p=0.225)$. Laser illumination here appeared primarily to reduce the average length of bouts of defensive treading-burying (DNQX/no laser mean: $2.3 \pm 0.4 \mathrm{~s} ; \mathrm{DNQX} /$ laser mean: $1.0 \pm 0.4 \mathrm{~s}$; Wilcoxon: $Z=2.201$, $p=0.028, r=0.90)$, as the number of defensive bouts emitted during the session was not changed (DNQX/no laser: $7.0 \pm 1.3$; DNQX/laser: $\left.5.2 \pm 2.8 ; t_{(5)}=0.921, p=0.399\right)$. In this sense, ChR2 excitation may have reduced the maintenance of fearmotivated behavior promoted by caudal DNQX microinjections, more than its initiation. Comparing the $5 \mathrm{~s}$ Laser ON bins versus $15 \mathrm{~s}$ OFF bins as the cycle was repeated, similar levels of defensive treading/burying behavior were seen in both ON and OFF portions of the cycle (normalized treading/burying laser ON: $12.0 \pm$ $7.1 \mathrm{~s}$; laser OFF: $\left.9.5 \pm 5.9 ; t_{(3)}=1.608, p=0.20\right)$. This again suggests that $5 \mathrm{~s}$ laser $\mathrm{ON}$ bins exerted a depressive effect on DNQX behaviors even during the $15 \mathrm{~s}$ period of laser OFF while ON/OFF bins were continuously cycled.

After vehicle microinjections in ChR2 rats, defensive behavior was at near-zero levels even in the loud environment, and adding 
laser had no further effect (vehicle/no laser: $1.4 \pm 1.0$; vehicle/ laser: $0.2 \pm 0.2$; Wilcoxon: $Z=1.069, p=0.285$ ).

One caudal ChR2 rat had bilateral NAc sites of caudal microinjection/fiber placement, but the tips were aligned within $<1$ mm only on one unilateral side, whereas on the contralateral side spacing was further apart. However, laser illumination in this unilaterally-aligned rat still reduced DNQX-elicited defensive treading behavior (from DNQX/no laser condition $=12 \mathrm{~s}$ treading; Fig. 7), suggesting again that a unilateral ChR2 neuronal depolarization, which overlaps with its DNQX-induced Fos plume can successfully reduce DNQX generation of motivated behavior even when the contralateral DNQX microinjection in NAc goes locally unopposed.

In ChR2 rats with rostral sites, adding simultaneous aligned laser illumination in the stressful environment again prevented DNQX from increasing food intake (drug $\times$ laser interaction: $F_{(1,4)}=8.696, p=0.042$; Figs. 5, 6). Laser illumination to DNQX markedly decreased food consumption below DNQX/no laser levels of the same rats (DNQX/laser: $1.2 \pm 1.4 \mathrm{~g}$; DNQX/no laser: $\left.5.2 \pm 1.8 \mathrm{~g} t_{(4)}=4.634, p=0.010, d=2.07\right)$, and similarly reduced DNQX-induced time spent eating (DNQX/laser 187.8 \pm $182.1 \mathrm{~s} ; \mathrm{DNQX} /$ no laser condition: $635.8 \pm 125.0 ; t_{(4)}=3.11, p=$ $0.036, d=1.39$ ). There were no differences in eating suppression between laser ON bins $(215.0 \pm 20.1 \mathrm{~s})$ and laser OFF bins (mean: $221.3 \pm 24.1 \mathrm{~s} ; t_{(2)}=1.462, p=0.281$ ) within the laser ON/OFF cycle during the DNQX/Laser test. Laser by itself in absence of DNQX did not alter eating in this group, as there was no difference in food intake between vehicle/laser and vehicle alone conditions for either rostral (vehicle/laser: $1.2 \pm$ $0.3 \mathrm{~g}$; vehicle alone: $1.3 \pm 0.4 \mathrm{~g} ; t_{(4)}=0.212, p=0.843$ ) or caudal sites (vehicle/laser: $2.0 \pm 0.5 \mathrm{~g}$; vehicle alone: $1.4 \pm$ $\left.0.6 \mathrm{~g} ; t_{(5)}=1.027, p=0.352\right)$.

For the ChR2 rat with unilateral cannula/fiber sites in rostral shell but contralateral sites in BNST, adding laser illumination still reversed the increase in eating otherwise produced by DNQX (DNQX alone: 3.5 g; Combined laser + DNQX = 1.5 g; Fig. 7). Similarly, another rostral rat with unilaterally aligned tips but contralaterally nonaligned tips (both sides in medial shell), still showed laser reversal of DNQX-induction of eating. These observations further support the suggestion that overlapping alignment of ChR2 excitation with DNQX microinjection on one side of NAc is sufficient to reverse effects of DNQX, even when the contralateral DNQX microinjection site is nonaligned (Table 2). This suggests that cross-hemisphere interaction could be involved in optogenetic modulation of DNQX-elicited motivations, although we note that lateralization also exists for NAc inhibition effects in generating motivated behavior (Stratford and Wirtshafter, 2012).

\section{Discussion}

Our findings demonstrate that optogenetic ChR2 excitation at same sites of DNQX microinjections in NAc medial shell can attenuate neurobiological recruitment of limbic circuitry, and reduce or reverse generation of intense appetitive or defensive behaviors otherwise elicited by those microinjections (Stratford and Kelley, 1997; Echo et al., 2001; Reynolds and Berridge, 2003, 2008; Richard and Berridge, 2011, 2013).

Optogenetic reversals of DNQX-elicited motivation appeared to require that ChR2-laser excitation be at the same local NAc site as the DNQX microinjection. That is, reversals occurred only if the optic fiber tip was within $0.5 \mathrm{~mm}$ (or at least $0.8 \mathrm{~mm}$ ) of the DNQX microinjector tip, otherwise the laser became less effective. This suggests that optogenetic depolarization does not sim- ply produce an opposing motivational signal in NAc shell circuitry to counteract DNQX effects. Rather, ChR2 excitation of neurons presumably reverses the relative neuronal inhibitions caused locally by blockade of glutamate AMPA signals in the same NAc site.

\section{Support for NAc-inhibition hypothesis of motivation generation}

To our knowledge, these results provide the first direct evidence for the hypothesis that relative inhibition of localized NAc shell neurons is necessary for DNQX microinjections to induce appetitive or fearful motivations. Similar NAc neuronal inhibitions have been suggested to mediate appetitive and defensive behaviors elicited microinjections of a $\mathrm{GABA}_{\mathrm{A}}$ agonist, such as muscimol in NAc shell (Stratford and Kelley, 1997; Reynolds and Berridge, 2002; Stratford and Wirtshafter, 2012; Covelo et al., 2014). NAc neuronal inhibitions may release downstream VP, LH and VTA targets into relative excitation, by decreasing their tonic suppression by NAc GABA inputs (Ljungberg et al., 1991; Baldo et al., 2004; Stratford, 2005; Bromberg-Martin and Hikosaka, 2009; Tindell et al., 2009; Smith et al., 2011). Target excitation was supported here by observing Fos increases in VP, LH, VTA, and other limbic structures after NAc DNQX microinjections that caused intense motivated behaviors. Those distant neurobiological recruitments were also impeded here by the same NAc ChR2 excitations that produced behavioral reversals, supporting the hypothesis that released limbic target activation mediated the generation of motivated behaviors.

Conceivably, a role for NAc shell inhibition in generating motivations could help explain why optogenetic excitation of NAc D1-MSNs or BLA projections to NAc is reported to stop ingestive motivation (O'Connor et al., 2015; Millan et al., 2017). Here, however, we did not detect a significant reduction in spontaneous food intake from NAc laser ChR2 stimulation in rats with vehicle microinjections, although there was a trend toward reduced consumption. Still, our ChR2 depolarization was effective for blocking the intense eating otherwise produced by DNQX microinjections.

Our results extend the NAc inhibition hypothesis to include NAc generation of negative-valenced 'fear' motivation, as well as positive-valenced appetitive motivation. Defensive treading is an active-coping type of antipredator reaction to perceived threats (Owings and Coss, 1977; Treit et al., 1981). Defensive treading was reversed here by laser-induced ChR2 excitation at caudal NAc sites in a stressfully loud environment. Thus, the hypothesis that NAc inhibition is required for DNQX-generation applies to motivated behaviors of both positive and negative valence. Given that ChR2 effects were identified here with hSyn promoter that infected all local neurons, it will be of interest for future studies to target specific subtypes of NAc neurons (e.g., D1 dopamine receptor-expressing MSNs; D2 receptor-expressing MSNs; etc.) to parse their relative contributions to these effects.

\section{Alternative pharmacological DNQX effects insufficient to cause motivations}

In addition to relative inhibition of NAc neurons, other plausible hypotheses could have explained how DNQX microinjections in NAc shell generate motivations. For example, pharmacological effects of AMPA blockade on neuronal function, which occur in parallel with relative inhibition, could have been more important than neuronal inhibition per se. Such parallel effects might include postsynaptic second messenger signals and gene transcription changes in MSNs. Alternatively, though DNQX is generally 
viewed as an AMPA postsynaptic receptor antagonist, it has been also reported to excite postsynaptic neurons (Menuz et al., 2007; Lee et al., 2010). Additionally, DNQX can act as a competitive antagonist for kainate receptors on presynaptic axon terminals, which might further alter signals in NAc (Tarazi et al., 1998a,b). Such effects could have been a primary mechanism for DNQX generation of motivation, but might not have been effectively opposed by laser ChR2 excitation of local neurons. However, our finding that ChR2 laser depolarization of local NAc neurons successfully reversed DNQX-induction of appetitive and defensive motivations suggests that local neural inhibition is indeed required, and that other alternative neurobiological effects are not sufficient in absence of NAc neuronal inhibition.

\section{Anatomical valence gradient and environmental switching of site valence}

In standard laboratory conditions here, DNQX microinjections at both rostral and caudal shell sites generated increases in appetitive eating behavior. However, a test environment with stressfully loud noise (rock music) caused DNQX at caudal shell sites instead to generate negatively-valenced 'fearful' motivation (i.e., defensive treading). The difference between anatomical sites replicates our previous reports of a rostrocaudal valence gradient of 'desire' versus 'dread' in NAc medial shell for DNQX effects (Reynolds and Berridge, 2001, 2002, 2008; Richard and Berridge, 2011; Richard et al., 2013). That anatomical difference also fits related reports of different affective functions or neurobiological features in rostral/caudal halves of NAc medial shell (Thompson and Swanson, 2010; Zahm et al., 2013; Reed et al., 2018; Trouche et al., 2019).

Similarly, the ability of changes in environment ambience to switch between appetitive versus defensive effects replicates our previous reports that switching from the standard laboratory to a stressfully noisy-bright environment switches the valence of DNQX-induced motivation at NAc sites to negatively 'fearful' (Reynolds and Berridge, 2008; Richard and Berridge, 2011). However, results here differed from our previous DNQX reports as our current cohort of rats appeared more strongly biased overall toward positive valence. Specifically, DNQX microinjections elicited appetitive food intake even at caudal sites in the standard laboratory environment, whereas our previous studies found that caudal DNQX evoked mostly defensive behavior. Further, in the stressfully loud environment, only caudal sites generated defensive treading behavior here, whereas in previous studies many rostral shell sites additionally switched to defensive valence. As caveat, we note that only louder sound was added to our stressful environment here, whereas previous studies of stress-induced switching also included brighter lights. We did not compare combinations of light and sound here, but it is possible that adding brighter light or other stressful stimuli might have expanded the fear-generating zone further into the rostral medial shell, as in previous studies (Reynolds and Berridge, 2008; Richard and Berridge, 2011).

Still, the lack of defensive behavior at caudal sites in the standard laboratory suggests a difference in affective reactivity between current rats versus previous studies. Although the reason for the difference remains unclear, several explanations seem possible. For example, our current cohort was raised in a more enriched environment than previous cohorts. Current housing conditions include additional toys in home cages and always being housed in social groups, which might conceivably decrease chronic stress levels (Manouze et al., 2019) and reduce fearful reactivity (Clark and Galef, 1980). Also, behavioral test chambers here had taller walls to accommodate optogenetic cables, which might be perceived as more sheltering and less anxiogenic. Finally, genetic drift in rat colonies may have altered emotional reactivity over several years. To know which factors are actually responsible for modulating the affective valence of NAc DNQX effects would require further investigation.

\section{Contrary role of NAc depolarizations in motivation}

Despite ample evidence for the NAc inhibition hypothesis for motivation as described, we note there is also evidence to support a paradoxically opposite hypothesis: that neuronal excitations in the NAc shell can elicit appetitive motivation. For example, decades of electrode self-stimulation studies suggested that neuronal excitations in NAc are reinforcing (Rolls, 1971; Mogenson et al., 1979; Van Ree and Otte, 1980; Phillips, 1984). Optogenetic studies similarly show that NAc MSN excitation can generate intense incentive motivation, reflected in either consummatory intake or appetitive instrumental measures (Lobo et al., 2010; Koo et al., 2014; Soares-Cunha et al., 2016; Cole et al., 2018). How can NAc excitation effects be reconciled with NAc inhibition effects in generating appetitive and defensive motivations?

There are several possibilities. For example, NAc excitations may excite lateral inhibition, via inhibitory GABAergic interneurons that produce local inhibitions of other NAc neurons. Indeed, ChR2 excitation of MSNs does inhibit at least some local NAc neurons (Kravitz and Kreitzer, 2011). Alternatively, NAc neurons might have multiple excitatory and inhibitory modes for motivational functions, through bimodal "up" versus "down" states that gate cortical and mesolimbic inputs (O'Donnell and Grace, 1995; O'Donnell et al., 1999). Finally, excitation and inhibition might recruit different NAc neuronal ensembles, defined as subsets with coordinated firing patterns, which have distinct downstream consequences (Pennartz et al., 1994; O'Donnell et al., 1999).

\section{Conclusion}

Our results indicate that local NAc neuronal inhibition is a necessary mechanism for DNQX microinjections in medial shell to generate either appetitive or defensive motivation. Together, these findings support the hypothesis that inhibition of NAc medial shell neurons is an important mechanism for generating intense motivation states of both positive and negative valence.

\section{References}

Baldo BA, Gual-Bonilla L, Sijapati K, Daniel RA, Landry CF, Kelley AE (2004) Activation of a subpopulation of orexin/hypocretin-containing hypothalamic neurons by GABAA receptor-mediated inhibition of the nucleus accumbens shell, but not by exposure to a novel environment. Eur J Neurosci 19:376-386.

Bromberg-Martin ES, Hikosaka O (2009) Midbrain dopamine neurons signal preference for advance information about upcoming rewards. Neuron 63:119-126.

Carlezon WA Jr, Wise RA (1996) Microinjections of phencyclidine (PCP) and related drugs into nucleus accumbens shell potentiate medial forebrain bundle brain stimulation reward. Psychopharmacology 128:413420 .

Carlezon WA Jr, Thomas MJ (2009) Biological substrates of reward and aversion: a nucleus accumbens activity hypothesis. Neuropharmacology 56:122-132.

Castro DC, Berridge KC (2017) Opioid and orexin hedonic hotspots in rat orbitofrontal cortex and insula. Proc Natl Acad Sci U S A 114: E9125-E9134.

Cheer JF, Heien ML, Garris PA, Carelli RM, Wightman RM (2005) Simultaneous dopamine and single-unit recordings reveal accumbens GABAergic responses: implications for intracranial self-stimulation. Proc Natl Acad Sci U S A 102:19150-19155. 
Clark MM, Galef BG Jr (1980) Effects of rearing environment on adrenal weights, sexual development, and behavior in gerbils: an examination of Richter's domestication hypothesis. J Comp Physiol Psychol 94:857-863.

Cole SL, Robinson MJF, Berridge KC (2018) Optogenetic self-stimulation in the nucleus accumbens: D1 reward versus D2 ambivalence. PLoS One 13:e0207694.

Covelo IR, Patel ZI, Luviano JA, Stratford TR, Wirtshafter D (2014) Manipulation of GABA in the ventral pallidum, but not the nucleus accumbens, induces intense, preferential, fat consumption in rats. Behav Brain Res 270:316-325.

De Boer SF, Koolhaas JM (2003) Defensive burying in rodents: ethology, neurobiology and psychopharmacology. Eur J Pharmacol 463:145-161.

Echo JA, Lamonte N, Christian G, Znamensky V, Ackerman TF, Bodnar RJ (2001) Excitatory amino acid receptor subtype agonists induce feeding in the nucleus accumbens shell in rats: opioid antagonist actions and interactions with mu-opioid agonists. Brain Res 921:86-97.

Faure A, Richard JM, Berridge KC (2010) Desire and dread from the nucleus accumbens: cortical glutamate and subcortical GABA differentially generate motivation and hedonic impact in the rat. PLoS One 5:e11223.

Heimer L, Zahm DS, Churchill L, Kalivas PW, Wohltmann C (1991) Specificity in the projection patterns of accumbal core and shell in the rat. Neuroscience 41:89-125.

Herdegen T, Leah JD (1998) Inducible and constitutive transcription factors in the mammalian nervous system: control of gene expression by Jun, Fos and Krox, and CREB/ATF proteins. Brain Res Brain Res Rev 28: $370-490$.

Humphries MD, Prescott TJ (2010) The ventral basal ganglia, a selection mechanism at the crossroads of space, strategy, and reward. Prog Neurobiol 90:385-417.

Koo JW, Lobo MK, Chaudhury D, Labonté B, Friedman A, Heller E, Peña CJ, Han MH, Nestler EJ (2014) Loss of BDNF signaling in DIR-expressing NAc neurons enhances morphine reward by reducing GABA inhibition. Neuropsychopharmacology 39:2646-2653.

Krause M, German PW, Taha SA, Fields HL (2010) A pause in nucleus accumbens neuron firing is required to initiate and maintain feeding. J Neurosci 30:4746-4756.

Kravitz AV, Kreitzer AC (2011) Optogenetic manipulation of neural circuitry in vivo. Curr Opin Neurobiol 21:433-439.

Lee SH, Govindaiah G, Cox CL (2010) Selective excitatory actions of DNQX and CNQX in rat thalamic neurons. J Neurophysiol 103:1728-1734.

Ljungberg T, Apicella P, Schultz W (1991) Responses of monkey midbrain dopamine neurons during delayed alternation performance. Brain Res 567:337-341.

Lobo MK, Covington HE 3rd, Chaudhury D, Friedman AK, Sun H, DamezWerno D, Dietz DM, Zaman S, Koo JW, Kennedy PJ, Mouzon E, Mogri M, Neve RL, Deisseroth K, Han MH, Nestler EJ (2010) Cell type-specific loss of BDNF signaling mimics optogenetic control of cocaine reward. Science 330:385-390.

Lu XY, Ghasemzadeh MB, Kalivas PW (1998) Expression of D1 receptor, D2 receptor, substance $P$ and enkephalin messenger RNAs in the neurons projecting from the nucleus accumbens. Neuroscience 82:767-780.

Maldonado-Irizarry CS, Swanson CJ, Kelley AE (1995) Glutamate receptors in the nucleus accumbens shell control feeding behavior via the lateral hypothalamus. J Neurosci 15:6779-6788.

Manouze H, Ghestem A, Poillerat V, Bennis M, Ba-M'hamed S, Benoliel JJ, Becker C, Bernard C (2019) Effects of single cage housing on stress, cognitive, and seizure parameters in the rat and mouse pilocarpine models of epilepsy. eNeuro 6:ENEURO.0179-18.2019.

Menuz K, Stroud RM, Nicoll RA, Hays FA (2007) TARP auxiliary subunits switch AMPA receptor antagonists into partial agonists. Science 318: 815-817.

Meredith GE, Baldo BA, Andrezjewski ME, Kelley AE (2008) The structural basis for mapping behavior onto the ventral striatum and its subdivisions. Brain Struct Funct 213:17-27.

Millan EZ, Kim HA, Janak PH (2017) Optogenetic activation of amygdala projections to nucleus accumbens can arrest conditioned and unconditioned alcohol consummatory behavior. Neuroscience 360:106-117.

Mogenson GJ, Takigawa M, Robertson A, Wu M (1979) Self-stimulation of the nucleus accumbens and ventral tegmental area of tsai attenuated by microinjections of spiroperidol into the nucleus accumbens. Brain Res 171:247-259.

Mogenson GJ, Swanson LW, Wu M (1983) Neural projections from nucleus accumbens to globus pallidus, substantia innominata, and lateral preoptic-lateral hypothalamic area: an anatomical and electrophysiological investigation in the rat. J Neurosci 3:189-202.

O'Connor EC, Kremer Y, Lefort S, Harada M, Pascoli V, Rohner C, Lüscher C (2015) Accumbal D1R neurons projecting to lateral hypothalamus authorize feeding. Neuron 88:553-564.

O'Donnell P, Grace AA (1995) Synaptic interactions among excitatory afferents to nucleus accumbens neurons: hippocampal gating of prefrontal cortical input. J Neurosci 15:3622-3639.

O’Donnell P, Greene J, Pabello N, Lewis BL, Grace AA (1999) Modulation of cell firing in the nucleus accumbens. Ann N Y Acad Sci 877:157-175.

Owings DH, Coss RG (1977) Snake mobbing by California ground squirrels: adaptive variation and ontogeny. Behaviour 62:50-69.

Paxinos G, Watson C (2007) The rat brain in stereotaxic coordinates, 6th ed. New York: Elsevier.

Pennartz CM, Groenewegen HJ, Lopes da Silva FH (1994) The nucleus accumbens as a complex of functionally distinct neuronal ensembles: an integration of behavioural, electrophysiological and anatomical data. Prog Neurobiol 42:719-761.

Phillips AG (1984) Brain reward circuitry: a case for separate systems. Brain Res Bull 12:195-201.

Reed SJ, Lafferty CK, Mendoza JA, Yang AK, Davidson TJ, Grosenick L, Deisseroth K, Britt JP (2018) Coordinated reductions in excitatory input to the nucleus accumbens underlie food consumption. Neuron 99: $1260-1273 . e 4$.

Reynolds SM, Berridge KC (2001) Fear and feeding in the nucleus accumbens shell: rostrocaudal segregation of GABA-elicited defensive behavior versus eating behavior. J Neurosci 21:3261-3270.

Reynolds SM, Berridge KC (2002) Positive and negative motivation in nucleus accumbens shell: bivalent rostrocaudal gradients for GABA-elicited eating, taste "liking"/“disliking" reactions, place preference/avoidance, and fear. J Neurosci 22:7308-7320.

Reynolds SM, Berridge KC (2003) Glutamate motivational ensembles in nucleus accumbens: rostrocaudal shell gradients of fear and feeding. Eur J Neurosci 17:2187-2200.

Reynolds SM, Berridge KC (2008) Emotional environments retune the valence of appetitive versus fearful functions in nucleus accumbens. Nat Neurosci 11:423-425.

Richard JM, Berridge KC (2011) Nucleus accumbens dopamine/glutamate interaction switches modes to generate desire versus dread: $D_{1}$ alone for appetitive eating but $D_{1}$ and $D_{2}$ together for fear. J Neurosci 31: $12866-12879$.

Richard JM, Berridge KC (2013) Prefrontal cortex modulates desire and dread generated by nucleus accumbens glutamate disruption. Biol Psychiatry 73:360-370.

Richard JM, Plawecki AM, Berridge KC (2013) Nucleus accumbens GABAergic inhibition generates intense eating and fear that resists environmental retuning and needs no local dopamine. Eur J Neurosci 37: $1789-1802$.

Roitman MF, Wheeler RA, Wightman RM, Carelli RM (2008) Real-time chemical responses in the nucleus accumbens differentiate rewarding and aversive stimuli. Nat Neurosci 11:1376-1377.

Rolls ET (1971) Contrasting effects of hypothalamic and nucleus accumbens septi self-stimulation on brain stem single unit activity and cortical arousal. Brain Res 31:275-285.

Smith KS, Berridge KC, Aldridge JW (2011) Disentangling pleasure from incentive salience and learning signals in brain reward circuitry. Proc Natl Acad Sci U S A 108:E255-E264.

Soares-Cunha C, Coimbra B, David-Pereira A, Borges S, Pinto L, Costa P, Sousa N, Rodrigues AJ (2016) Activation of D2 dopamine receptorexpressing neurons in the nucleus accumbens increases motivation. Nat Commun 7:11829.

Soares-Cunha C, Coimbra B, Domingues AV, Vasconcelos N, Sousa N, Rodrigues AJ (2018) Nucleus accumbens microcircuit underlying D2MSN-driven increase in motivation. eNeuro 5:ENEURO.0386-18.2018.

Stratford TR (2005) Activation of feeding-related neural circuitry after unilateral injections of muscimol into the nucleus accumbens shell. Brain Res 1048:241-250.

Stratford TR, Kelley AE (1997) GABA in the nucleus accumbens shell participates in the central regulation of feeding behavior. J Neurosci 17: $4434-4440$.

Stratford TR, Wirtshafter D (2012) Evidence that the nucleus accumbens 
shell, ventral pallidum, and lateral hypothalamus are components of a lateralized feeding circuit. Behav Brain Res 226:548-554.

Taha SA, Fields HL (2006) Inhibitions of nucleus accumbens neurons encode a gating signal for reward-directed behavior. J Neurosci 26:217-222.

Tarazi FI, Campbell A, Baldessarini RJ (1998a) Effects of hippocampal lesions on striatolimbic ionotropic glutamatergic receptors. Neurosci Lett 250:13-16.

Tarazi FI, Campbell A, Yeghiayan SK, Baldessarini RJ (1998b) Localization of ionotropic glutamate receptors in caudate-putamen and nucleus accumbens septi of rat brain: comparison of NMDA, AMPA, and kainate receptors. Synapse 30:227-235.

Thompson RH, Swanson LW (2010) Hypothesis-driven structural connectivity analysis supports network over hierarchical model of brain architecture. Proc Natl Acad Sci U S A 107:15235-15239.

Tindell AJ, Smith KS, Berridge KC, Aldridge JW (2009) Dynamic computation of incentive salience: "wanting" what was never "liked". J Neurosci 29:12220-12228.

Treit D, Pinel JP, Fibiger HC (1981) Conditioned defensive burying: a new paradigm for the study of anxiolytic agents. Pharmacol Biochem Behav 15:619-626.

Trouche S, Koren V, Doig NM, Ellender TJ, El-Gaby M, Lopes-Dos-Santos V, Reeve HM, Perestenko PV, Garas FN, Magill PJ, Sharott A, Dupret D
(2019) A hippocampus-accumbens tripartite neuronal motif guides appetitive memory in space. Cell 176:1393-1406.e16.

Usuda I, Tanaka K, Chiba T (1998) Efferent projections of the nucleus accumbens in the rat with special reference to subdivision of the nucleus: biotinylated dextran amine study. Brain Res 797:73-93.

Van Ree JM, Otte AP (1980) Effects of (Des-Tyr1)-gamma-endorphin and alpha-endorphin as compared to haloperidol and amphetamine on nucleus accumbens self-stimulation. Neuropharmacology 19:429-434.

Warlow SM, Robinson MJF, Berridge KC (2017) Optogenetic central amygdala stimulation intensifies and narrows motivation for cocaine. J Neurosci 37:8330-8348.

Wheeler RA, Twining RC, Jones JL, Slater JM, Grigson PS, Carelli RM (2008) Behavioral and electrophysiological indices of negative affect predict cocaine self-administration. Neuron 57:774-785.

Zahm DS, Heimer L (1990) Two transpallidal pathways originating in the rat nucleus accumbens. J Comp Neurol 302:437-446.

Zahm DS, Parsley KP, Schwartz ZM, Cheng AY (2013) On lateral septumlike characteristics of outputs from the accumbal hedonic "hotspot" of Peciña and Berridge with commentary on the transitional nature of basal forebrain "boundaries". J Comp Neurol 521:50-68.

Zhou L, Furuta T, Kaneko T (2003) Chemical organization of projection neurons in the rat accumbens nucleus and olfactory tubercle. Neuroscience 120:783-798. 